\title{
Radiolabeled PSMA Inhibitors
}

\author{
Oliver C. Neels ${ }^{1, * \mathbb{C}}$, Klaus Kopka ${ }^{1,2} \mathbb{D}$, Christos Liolios ${ }^{3,4} \mathbb{D}$ and Ali Afshar-Oromieh ${ }^{5}$ \\ 1 Institute of Radiopharmaceutical Cancer Research, Helmholtz-Zentrum Dresden-Rossendorf (HZDR), \\ Bautzner Landstrasse 400, 01328 Dresden, Germany; k.kopka@hzdr.de \\ 2 Faculty of Chemistry and Food Chemistry, School of Science, Technical University Dresden, \\ Mommsenstrasse 4, 01062 Dresden, Germany \\ 3 Department of Pharmaceutical Chemistry, Faculty of Pharmacy, National \& Kapodistrian University of \\ Athens, Zografou, 15771 Athens, Greece; liolios.xr@gmail.com \\ 4 INRASTES, Radiochemistry Laboratory, NCSR “Demokritos”, Ag. Paraskevi Attikis, 15310 Athens, Greece \\ 5 Department of Nuclear Medicine, Bern University Hospital (Inselspital), Freiburgstrasse 18, \\ 3010 Bern, Switzerland; ali.afshar@insel.ch \\ * Correspondence: o.neels@hzdr.de
}

check for

updates

Citation: Neels, O.C.; Kopka, K.; Liolios, C.; Afshar-Oromieh, A. Radiolabeled PSMA Inhibitors. Cancers 2021, 13, 6255. https:// doi.org/10.3390/cancers13246255

Academic Editor: Radka Stoyanova

Received: 4 November 2021

Accepted: 11 December 2021

Published: 13 December 2021

Publisher's Note: MDPI stays neutral with regard to jurisdictional claims in published maps and institutional affiliations.

Copyright: (C) 2021 by the authors. Licensee MDPI, Basel, Switzerland. This article is an open access article distributed under the terms and conditions of the Creative Commons Attribution (CC BY) license (https:// creativecommons.org/licenses/by/ $4.0 /)$.
Simple Summary: Prostate cancer remains one of the leading causes of cancer death in men worldwide. Despite the recent success in the development and clinical application of radiopharmaceuticals targeting the prostate-specific membrane antigen (PSMA) for diagnosis and endoradiotherapy of prostate cancer, more research is ongoing to further investigate and improve patient care and quality of life. Herein, an overview of novel developments and applications for small molecule and low-molecular weight radiolabeled PSMA inhibitors with an outlook to clinical translation is given.

\begin{abstract}
PSMA has shown to be a promising target for diagnosis and therapy (theranostics) of prostate cancer. We have reviewed developments in the field of radio- and fluorescence-guided surgery and targeted photodynamic therapy as well as multitargeting PSMA inhibitors also addressing albumin, GRPr and integrin $\alpha_{\mathrm{V}} \beta_{3}$. An overview of the regulatory status of PSMA-targeting radiopharmaceuticals in the USA and Europe is also provided. Technical and quality aspects of PSMA-targeting radiopharmaceuticals are described and new emerging radiolabeling strategies are discussed. Furthermore, insights are given into the production, application and potential of alternatives beyond the commonly used radionuclides for radiolabeling PSMA inhibitors. An additional refinement of radiopharmaceuticals is required in order to further improve dose-limiting factors, such as nephrotoxicity and salivary gland uptake during endoradiotherapy. The improvement of patient treatment achieved by the advantageous combination of radionuclide therapy with alternative therapies is also a special focus of this review.
\end{abstract}

Keywords: PSMA; prostate-specific membrane antigen; PSMA inhibitor; radiolabeling; PET; SPECT; fluorescence; endoradiotherapy; theranostics; radioguided surgery; fluorescence-guided surgery; targeted photodynamic therapy; radionuclides

\section{Introduction}

Radiopharmaceuticals targeting the prostate-specific membrane antigen (PSMA) have seen great success in Nuclear Medicine for both diagnosis and endoradiotherapy of prostate cancer ( $\mathrm{PCa}$ ) [1,2] thus paving the way for (radio)theranostics [3-5] with guidelines being published by international experts and societies [6-19].

$\left[{ }^{68} \mathrm{Ga}\right]$ Ga-PSMA-11 (gozetotide) [20-23] and [ $\left.{ }^{18} \mathrm{~F}\right] \mathrm{DCFPyL}$ (piflufolastat) [24-27] as diagnostic imaging agents have been approved in the US by the Food and Drug Administration (FDA) since 1st December 2020 [28-32] and 27th May 2021 [33,34], respectively. Meanwhile, $\left[{ }^{18}\right.$ F]PSMA-1007 [35-38] is awaiting regulatory approval in European countries pending a phase 3 clinical study being completed (NCT04102553). [ ${ }^{99 m}$ Tc]Tc-MIP-1404 (trofolostat) is a highly promising SPECT agent [39-42]. Monographs have been published 
by the European Directorate for the Quality of Medicines (EDQM) for $\left[{ }^{68} \mathrm{Ga}\right] \mathrm{Ga}-\mathrm{PSMA}-11$ (Ph. Eur. Monograph 3044) and $\left[{ }^{18} \mathrm{~F}\right] \mathrm{PSMA}-1007$ (Ph. Eur. Monograph 3116) which came into force 1st April 2021 and 1st July 2021, respectively [43]. Alberts et al. recently reported an overview that evaluated the most commonly used PET radiopharmaceuticals for the diagnosis of prostate cancer [44].

The most prominent ligands used for PSMA-targeted endoradiotherapy with beta ${ }^{-}$ and alpha emitters are PSMA I\&T [45-48] and PSMA-617 (vipivotide tetraxetan) [49-52]. The latter radiopharmaceutical is expected to receive marketing authorization in several countries after successfully accomplishing a phase 3 clinical study using $\left[{ }^{177} \mathrm{Lu}\right] \mathrm{Lu}-\mathrm{PSMA}-$ 617 (NCT03511664) [53-55]. In response to this predicted breakthrough, infrastructural challenges should be addressed in the capacity planning of Nuclear Medicine therapy departments in the future [56]. Moreover, the experience of patients enrolled in a clinical trial involving radioactive treatment [57] and the necessity of a proper patient selection by PET imaging prior endoradiotherapy demands further attention [58-60].

In the future, a much broader acceptance and application of PSMA theranostics can be anticipated when diagnosis and treatment are being reimbursed by health insurances [61]. Amongst the aforementioned radiopharmaceuticals, several other radioligands targeting PSMA are either under clinical investigation or have been translated into a clinical setting (Table 1) [19,62]. The combination of radionuclide therapy with other treatment strategies offers new opportunities for patient care, these potential alternatives have been reviewed by Sandhu et al. and Zhang et al. [63,64]. This review aims to provide an overview of novel developments and applications in the area of small-molecule and low-molecular weightbased radiolabeled PSMA inhibitors [65], keeping their prospective clinical translation in mind.

Table 1. PSMA-targeting radiopharmaceuticals marketed, under clinical investigation or in a clinical setting.

\begin{tabular}{|c|c|c|c|c|}
\hline Radiopharmaceutical & Brand Name & Radionuclide & Reference & $\begin{array}{c}\text { Number of Clinical } \\
\text { Trials }{ }^{1} \\
\text { (Completed/Ongoing) }\end{array}$ \\
\hline DCFPyL & PYLARIFY & ${ }^{18} \mathrm{~F}$ & {$[24,66]^{2}$} & $14 / 51$ \\
\hline PSMA-11 & $\begin{array}{c}\text { Illuccix }^{3 /} \text { isoPROtrace-11 } \\
-\end{array}$ & $\begin{array}{c}{ }^{68} \mathrm{Ga} \\
{ }^{18} \mathrm{~F}\end{array}$ & $\begin{array}{c}{[20,67]^{2,4}} \\
{[68,69]}\end{array}$ & $\begin{array}{c}24 / 89 \\
2 /-\end{array}$ \\
\hline PSMA-1007 & - & ${ }^{18} \mathrm{~F}$ & {$[35,70]^{4}$} & $2 / 13$ \\
\hline PSMA-617 & - & $\begin{array}{l}{ }^{44} \mathrm{Sc} \\
{ }^{64} \mathrm{Cu} \\
{ }^{68} \mathrm{Ga} \\
{ }^{111} \mathrm{In} \\
{ }^{152} \mathrm{~Tb} \\
{ }^{177} \mathrm{Lu} \\
{ }^{225} \mathrm{Ac}\end{array}$ & $\begin{array}{c}{[71,72]} \\
{[73]} \\
{[49,74]} \\
{[75]} \\
{[76]} \\
{[49,77]} \\
{[78]}\end{array}$ & $\begin{array}{l}-/- \\
-/- \\
1 / 3 \\
-/- \\
-/- \\
1 / 17 \\
-/ 2\end{array}$ \\
\hline PSMA I\&T & - & $\begin{array}{l}{ }^{68} \mathrm{Ga} \\
{ }^{111} \mathrm{In} \\
{ }^{177} \mathrm{Lu} \\
{ }^{225} \mathrm{Ac}\end{array}$ & $\begin{array}{c}{[45]} \\
{[79,80]} \\
{[45]} \\
{[48]}\end{array}$ & $\begin{array}{l}-/- \\
-/ 1 \\
-/ 5 \\
-/-\end{array}$ \\
\hline PSMA I\&S & - & ${ }^{99 \mathrm{~m}} \mathrm{Tc}$ & [81] & $-/ 3$ \\
\hline MIP-1404 & - & ${ }^{99 \mathrm{~m}} \mathrm{Tc}$ & {$[39,82]$} & $6 /-$ \\
\hline rhPSMA-7.3 & - & 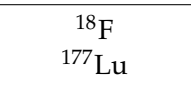 & $\begin{array}{l}{[83,84]} \\
{[85,86]}\end{array}$ & $\begin{array}{l}1 / 3 \\
-/-\end{array}$ \\
\hline JK-PSMA-7 & - & ${ }^{18} \mathrm{~F}$ & {$[87,88]$} & $-/-$ \\
\hline THP-PSMA & GalliProst & ${ }^{68} \mathrm{Ga}$ & {$[89,90]$} & $1 / 1$ \\
\hline PSMA-R2 & - & $\begin{array}{l}{ }^{68} \mathrm{Ga} \\
{ }^{177} \mathrm{Lu}\end{array}$ & - & $\begin{array}{l}1 / 1 \\
0 / 1\end{array}$ \\
\hline
\end{tabular}

${ }^{1}$ According to clinicaltrials.gov accessed on 26 October $2021 .{ }^{2}$ FDA-approved. ${ }^{3}$ TGA-approved. ${ }^{4}$ Ph. Eur. monograph applicable. 


\section{Quality and Technical Improvements of PSMA Inhibitors}

\subsection{Quality Issues and Technical Improvements}

Although radiolabeled PSMA inhibitors are used extensively for clinical applications, including radiotracers for which quality standards have been established by legally applicable specific monographs [43], special care needs to be taken during radiosynthesis and quality control of the radiopharmaceuticals.

Iudicello et al. showed that PSMA-11, which is used as a reference standard and precursor for the synthesis of $\left[{ }^{68} \mathrm{Ga}\right] \mathrm{Ga}-\mathrm{PSMA}-11$, when dissolved in acidic aqueous solution forms a ${ }^{\text {nat }} \mathrm{Fe}-\mathrm{PSMA}-11$ complex (a side product with two diastereomeric forms similar to the ones previously reported for $\left.\left[{ }^{68} \mathrm{Ga}\right] \mathrm{Ga}-\mathrm{PSMA}-11\right)$ resulting thus, in lower radiochemical yield, chemical purity and radiochemical purity [91,92]. As a consequence, for storage of the PSMA-11 solution, EDTA was added to transchelate the Fe iron from the HBED-CC chelator.

Five-membered ring systems can be formed as radioactive side-products by a thermally mediated and $\mathrm{pH}$-dependent condensation reaction of the Glu-urea-Lys binding motif during synthesis of $\left[{ }^{177} \mathrm{Lu}\right] \mathrm{Lu}-\mathrm{PSMA}-617$ [93]. These side-products did not show any binding affinity to PSMA and were rapidly excreted via the kidneys from the body of five patients. The synthesis of $\left[{ }^{177} \mathrm{Lu}\right] \mathrm{Lu}-\mathrm{PSMA}-617$ could be optimized by adjustment of $\mathrm{pH}$ and temperature and subsequent reduction of side-products, however, the risk of formation of unwanted radioactive side-products for PSMA inhibitors bearing the Glu-urea-Lys binding motif still remains [93].

Reaction temperature during radiolabeling plays an important role as shown above. Attempts have been made to replace DOTA, which requires time and heating for complexing radiometals, with a different chelator that allows low temperature radiolabeling in particular for the alpha-particle emitting isotope ${ }^{225} \mathrm{Ac}$. Thiele et al. showed that the eighteen-membered macrocyclic chelator macropa is suitable to complex ${ }^{225} \mathrm{Ac}$ at room temperature (RT) in 5 min with high stability in human serum over 8 days [94]. Macropa was then conjugated to the PSMA/albumin binding ligand RPS-070 and radiolabeled with ${ }^{225} \mathrm{Ac}$ within 20 min at RT. [ $\left.{ }^{225} \mathrm{Ac}\right]$ Ac-macropa-RPS-070 was tested in LNCaP tumor bearing mice where it showed high in vivo stability and high kidney uptake after $4 \mathrm{~h}(52 \pm 16 \%$ $\mathrm{ID} / \mathrm{g})$, which then cleared rapidly, while tumor uptake $(13 \pm 3 \% \mathrm{ID} / \mathrm{g})$ washout was slower. Reissig et al. expanded the "macropa"-principle by adding one or two alkyne moieties for conjugation of biomolecules using the copper-catalyzed azide-alkyne-cycloaddition [95]. A PSMA binding block was attached via click chemistry to obtain either the monomer mcp-M-PSMA or the dimer mcp-D-PSMA. Radiolabeling was done within $1 \mathrm{~h}$ at RT, both $\left[{ }^{225} \mathrm{Ac}\right] \mathrm{Ac}-\mathrm{mcp}-\mathrm{M}$-PSMA and $\left[{ }^{225} \mathrm{Ac}\right] \mathrm{Ac}-\mathrm{mcp}$-D-PSMA were evaluated in vitro and in vivo using LNCaP cells and the corresponding xenograft mouse model. It is noticeable that the tumor uptake for the monomer was higher within the first hour and then decreased while the tumor uptake for the dimer constantly increased within $24 \mathrm{~h}$ making it more suitable for a therapy approach [95].

Radiopharmaceuticals are also prepared via so-called cold kits, for a long time established in Nuclear Medicine by reconstitution with the eluate of ${ }^{99 \mathrm{~m}} \mathrm{Tc}$ generators [96]. More recently, this approach has seen a wider application also for PET radiopharmaceuticals with three commercially available kits using either PSMA-11 (Illuccix and isoPROtrace-11) or THP-PSMA (GalliProst) for radiolabeling with the eluate of a ${ }^{68} \mathrm{Ge} /{ }^{68} \mathrm{Ga}$ generator [97]. Illuccix has been approved by the Australian Therapeutic Goods Administration (TGA) on 2nd November 2021 [98].

\subsection{Salivary Gland Uptake}

Uptake in the salivary glands is the dose-limiting factor during endoradiotherapy with small-molecule PSMA inhibitors, resulting in (partially reversible) xerostomia when applied with ${ }^{177} \mathrm{Lu}$, and severe to persistent xerostomia when applied with ${ }^{225} \mathrm{Ac}[50,51]$. The quality of life for patients can, therefore, be significantly impaired despite preventive strategies, e.g., injection of botulinum toxin, external cooling, or gustatory stimulation have 
been described [99-103]. The uptake mechanism of PSMA inhibitors in salivary glands has not been thoroughly investigated to date, a more comprehensive review concerning known mechanisms is described by Heynickx et al. [103]. Tönnesmann et al. showed in quantitative autoradiography experiments that in the salivary glands of pigs for smallmolecule and low-molecular weight PSMA inhibitors the uptake is highly non-specific and at the same time specific while the exact ratio is not yet understood [104]. Attempts to minimize the uptake of the PSMA-targeted radiopharmaceutical in the salivary glands have been made following the modifications at the inhibitor component. This resulted in low salivary gland uptake and very low tumor uptake [105]. Two independent preclinical studies demonstrated that additional substance amount-dependent administration of nonradioactive PSMA ligand (PSMA-11 or DCFPyL, respectively) and reduction of the effective molar activity significantly reduces the radioligand uptake $\left(\left[{ }^{177} \mathrm{Lu}\right] \mathrm{Lu}-\mathrm{PSMA}-617\right.$ or $\left[{ }^{18}\right.$ F]DCFPyL, respectively) in the salivary glands (Table 2$)[106,107]$. However, these promising results need to be confirmed in further preclinical and clinical studies.

Table 2. Biodistribution data of $\left[{ }^{177} \mathrm{Lu}\right] \mathrm{Lu}-\mathrm{PSMA}-617$ (5 pmoles) with co-injected non-radioactive PSMA-11 for tumor and selected non-target organs one hour after injection in athymic mice bearing PC-3 PIP tumors [106].

\begin{tabular}{cccc}
\hline $\begin{array}{c}\text { Added Amount of } \\
\text { “Cold" PSMA-11 } \\
\text { (Pmoles) }\end{array}$ & $\begin{array}{c}\text { Tumor Uptake (\% } \\
\text { ID/g) }\end{array}$ & $\begin{array}{c}\text { Kidney Uptake (\% } \\
\text { ID/g) }\end{array}$ & $\begin{array}{c}\text { Salivary Gland } \\
\text { Uptake (\% ID/g) }\end{array}$ \\
\hline 0 & $21.71 \pm 6.13$ & $123.14 \pm 52.52$ & $0.48 \pm 0.11$ \\
5 & $18.70 \pm 2.03$ & $132.31 \pm 47.40$ & $0.45 \pm 0.15$ \\
100 & $26.44 \pm 2.94$ & $84.29 \pm 78.25$ & $0.38 \pm 0.30$ \\
500 & $16.21 \pm 3.50$ & $2.12 \pm 1.88$ & $0.08 \pm 0.03$ \\
1000 & $13.52 \pm 3.68$ & $1.16 \pm 0.36$ & $0.09 \pm 0.07$ \\
2000 & $12.03 \pm 1.96$ & $0.64 \pm 0.23$ & $0.05 \pm 0.02$ \\
\hline
\end{tabular}

\section{PSMA Inhibitors for Guided Surgery}

\subsection{PSMA Inhibitors for Radioguided Surgery}

In addition to the properties for noninvasive single photon emission computed tomography (SPECT) or positron emission tomography (PET) imaging, the radiation exposed from the radionuclide bound to the PSMA inhibitor can also be used for the detection of tumor entities during intraoperative surgery using a gamma probe in a practice named radioguided surgery (RGS) [108].

PSMA I\&T and PSMA-617 radiolabeled with ${ }^{111}$ In were initially used for SPECT imaging and RGS $[75,79,80,109,110]$, with both showing detection rates lower than $\left[{ }^{68} \mathrm{Ga}\right] \mathrm{Ga}$ PSMA-11 [111]. However, due to the limited availability of [ $\left.{ }^{111} \mathrm{In}\right] \mathrm{InCl}_{3}$, PSMA I\&T derived Mas $3-y-n a l-k(S u b-K u E)$ (PSMA I\&S) was developed and radiolabeled with ${ }^{99}{ }^{\mathrm{m}} \mathrm{Tc}$ [81]. $\left[{ }^{99 \mathrm{~m}} \mathrm{Tc}\right] \mathrm{Tc}-\mathrm{PSMA}$ I\&S RGS using a gamma probe was applied in a clinical setting after identifying tumor lesions with $\left[{ }^{68} \mathrm{Ga}\right] \mathrm{Ga}-\mathrm{PSMA}-11$ PET $[112,113]$. In a study including 210 PCa patients, high detection rates were found for $\left[{ }^{99 \mathrm{~m}} \mathrm{Tc}\right] \mathrm{Tc}-\mathrm{PSMA}$ I\&S for PSA levels $>4 \mathrm{ng} / \mathrm{mL}$ [114]. The radiation dosimetry of [ $\left.{ }^{99 \mathrm{~m}} \mathrm{Tc}\right] \mathrm{Tc}-\mathrm{PSMA}$ I\&S, which was performed in a single-center study, resulted in comparable effective doses with other ${ }^{99 \mathrm{~m}}$ Tc radiopharmaceuticals and lower effective doses than either ${ }^{68} \mathrm{Ga}$ - or ${ }^{18} \mathrm{~F}$-radiolabeled PSMA inhibitors ([99m Tc]Tc-PSMA I\&S: $0.0052 \mathrm{mSv} / \mathrm{MBq},\left[{ }^{68} \mathrm{Ga}\right] \mathrm{Ga}-P S M A-11: 0.0236 \mathrm{mSv} / \mathrm{MBq}$, $\left[{ }^{18}\right.$ F]PSMA-1007: $\left.0.022 \mathrm{mSv} / \mathrm{MBq}\right)$ [115-117].

As an undesirable consequence of RGS, personnel are typically exposed to constant radiation from the radiopharmaceutical. The occupational radiation exposure for workers involved in RGS using [ ${ }^{99 \mathrm{~m}} \mathrm{Tc}$ ]Tc-PSMA I\&S was determined with a maximum dose of $0.32 \mathrm{mSv} /$ year for 100 procedures [118]. When laparoscopic gamma probes are used for sentinel lymph node dissection [119] they suffer from practical limitations, due to rotational impairment of the probe [120]. This limitation has been circumvented by the development of a drop-in probe, which can be controlled by grasps of the DaVinci robotic- 
assisted surgery system, thereby providing additional rotational freedom and reducing the radiation dose [121]. A first-in-human application has been reported for [ $\left.{ }^{99 \mathrm{~m}} \mathrm{Tc}\right] \mathrm{Tc}-\mathrm{PSMA}$ I\&S after preoperative $\left[{ }^{68} \mathrm{Ga}\right.$ ]Ga-PSMA-11 PET/CT [122]. In an experimental study with seven patients, the drop-in concept was tested with [ $\left.{ }^{68} \mathrm{Ga}\right] \mathrm{Ga}-\mathrm{PSMA}-11$ using a beta probe instead of a gamma probe. After an additional dose of approximately $70 \mathrm{MBq}\left[{ }^{68} \mathrm{Ga}\right] \mathrm{Ga}-$ PSMA-11 per patient prior surgery, the obtained surgical specimens were evaluated ex vivo using a DaVinci robotic system equipped with the drop-in beta probe [123]. Radiation dose to workers limits the use to 62 procedures/year of this technique, but improvements towards a lower occupational radiation dose are feasible. Alternative imaging technologies focusing on beta-radiation emission, e.g., Cerenkov luminescence imaging using [ $\left.{ }^{68} \mathrm{Ga}\right] \mathrm{Ga}-$ PSMA-11 are currently under early clinical investigation [124-130].

\subsection{PSMA Inhibitors for Fluorescence-Guided Surgery and/or Targeted Photodynamic Therapy}

Aside from radionuclide detection for radioguided surgery, an attractive alternative for intraoperative guided surgery is radiolabeled molecules functionalized with fluorescent dyes for optical/fluorescence imaging [131-134]. A variety of commercially available dyes with different absorptions and emission spectra used for dual-labeled imaging agents has been reported [135]. Dual-labeled agents allow preoperative nuclear imaging (prestaging/staging) and subsequent treatment planning while fluorescence imaging makes surgical tumor resection possible and more accurate due to the high spatial resolution.

Baranski et al. studied the PSMA-11 derived hybrid compound Glu-urea-Lys-HBEDCC-IRDye800CW in vitro and in vivo in LNCaP-tumor bearing mice and healthy pigs [136]. $\left[{ }^{68} \mathrm{Ga}\right] \mathrm{Ga}-\mathrm{Glu}$-urea-Lys-HBED-CC-IRDye800CW showed an increased tumor uptake in mice compared to [ ${ }^{68} \mathrm{Ga}$ ]Ga-PSMA-11 (13.66 $\pm 3.73 \%$ ID/g vs. $4.89 \pm 1.34 \%$ ID/g) $[136,137]$. Non-radiolabeled Glu-urea-Lys-HBED-CC-IRDye800CW has been investigated in healthy pigs using a DaVinci robotic system. A PSMA-specific fluorescence signal has been shown in vivo and ex vivo for both mice and pigs. More recently, the linker design of Glu-urea-LysHBED-CC-IRDye800CW was modified by insertion of histidine- and glutamic acid spacers $\left((\mathrm{HE})_{3}\right)$ near the PSMA binding motif to further reduce background uptake in non-target tissue and to accelerate excretion [138,139]. Glu-urea-Lys-(HE) 3 -HBED-CC-IRDye800CW (PSMA-914) was used in a proof-of-concept study, with a first, pre-operative PET/CT imaging, 1-day prior surgery in a patient with high-risk prostate carcinoma and a second PET/CT imaging, after the surgical removal of the primary tumor [140]. ${ }^{68}$ Ga-radiolabeled PSMA-914 and PSMA-914 alone were administered 1-h prior to PET imaging and DaVinci robot-assisted prostatectomy respectively.

Schottelius et al. conjugated the disulfonated analog of the far-red cyanine dye Cy5 to PSMA I\&T to obtain the hybrid imaging agent PSMA I\&F (DOTAGA-D-Lys $\left(\mathrm{N}_{\varepsilon}-\right.$ SulfoCy5)-D-(3-iodo)Tyr-D-(3-iodo)Tyr-D-Lys( $\left.\mathrm{N}_{\varepsilon}-\mathrm{Sub}-\mathrm{KuE}\right)$ [141]. Tumor uptake in LNCaP xenograft-bearing mice was comparable between $\left[{ }^{68} \mathrm{Ga}\right] \mathrm{Ga}-\mathrm{PSMA}$ I\&F and $\left[{ }^{68} \mathrm{Ga}\right] \mathrm{Ga}-\mathrm{PSMA}$ I\&T $(4.5 \pm 1.8 \%$ ID/g vs. $4.9 \pm 1.6 \%$ ID/g) while kidney uptake was almost doubled for $\left[{ }^{68} \mathrm{Ga}\right] \mathrm{Ga}-P S M A ~ I \& F(105.8 \pm 22.7 \%$ ID $/ \mathrm{g}$ vs. $53.3 \pm 9.0 \% \mathrm{ID} / \mathrm{g})$.

One limitation/challenge regarding the utilization of fluorescent dyes is that the detection efficacy of tumor lesions is limited to superficial tissue [142,143]. Certain dyes can also be used for photodynamic therapy [144]. In this approach, a dye can also simultaneously act as a photosensitizer which is selectively activated with long wavelength light, subsequently causing reactive oxygen species (ROS) formation leading to the induction of immediate cell death [108]. Derks et al. synthesized a variety of Glu-urea-Lys-based PSMA-targeting ligands conjugated to IRDye700DX [145]. The most promising candidate PSMA-N064 consists of a DOTAGA chelator, additional glutamic acid residues in the linker structure, a Glu-urea-Lys binding motif, and a fluorophore. After radiolabeling of PSMAN064 with ${ }^{111} \mathrm{In}$, an increased tumor uptake of up to $2 \mathrm{~h}$ post injection $(13.1 \pm 2.3 \% \mathrm{ID} / \mathrm{g})$ was determined in mice bearing LS1754T colon carcinoma cells transfected with human PSMA (LS1754T-PSMA). The tumors could be visualized using SPECT/CT and near infrared fluorescence scanners. Interestingly, the incorporation of the fluorophore leads to 
a higher internalization in tumor cells than the corresponding ligand without the dye $(15.1 \pm 0.8 \% \mathrm{ID} / \mathrm{g}$ vs. $6.7 \pm 1.1 \% \mathrm{ID} / \mathrm{g})$. Accordingly, the fluorophore parts may have a positive impact on tumor uptake $[136,145]$. Samples obtained from biopsies of human normal tissue could be distinguished from tumor tissue after incubation with PSMA-N064 using fluorescence imaging. In a proof-of-concept study for targeted photodynamic therapy, the incubation of LS1754T-PSMA cells with PSMA-N064 and exposure to NIR light resulted in reduced cell viability $(34 \pm 3.2 \%)$.

\section{Multitargeted PSMA Inhibitors}

\subsection{PSMA + Albumin}

PSMA inhibitors used for endoradiotherapy, such as PSMA-617 and PSMA I\&T are rapidly excreted via the kidneys, increasing the radiation exposure to these organs [146]. Introducing albumin-binding groups into the chemical structure of small molecules can increase their blood circulation time, which can potentially lead to enhanced tumor uptake, while the reduction of injected activity results in lower non-target tissue doses $[147,148]$.

The 4 - $(p$-iodophenyl)acetic acid moiety was employed as an albumin-binding group by Kelly et al. in radiotracers bearing a DOTA chelator and a urea-based PSMA binding-motif radiolabeled with ${ }^{131}$ I (RPS-025) and ${ }^{177} \mathrm{Lu}$ (RPS-063 \& RPS-067). This modification lead to a 4-fold higher tumor uptake compared to [ $\left.{ }^{177} \mathrm{Lu}\right] \mathrm{Lu}$-PSMA-617, however, kidney-uptake was still significantly high $[149,150]$. It was observed that the use of polyethylene glycol (PEG) linkers of varying lengths had a dramatic impact on PSMA binding affinity as well as blood clearance [150]. Replacement of the albumin-binding group 4-( $p$-iodophenyl)acetic acid moiety with 4-( $p$-iodophenyl)butanoic acid (RPS-072) further reduced radiation exposure to the kidney and blood clearance [151].

Benešová et al. used the 4-( $p$-iodophenyl)butanoic acid moiety as an albumin-binding group in a similar way and extended the linker entity with aspartate residues to counterbalance the lipophilicity of the albumin-binding group [152]. Three radioligands consisting of a DOTA chelator, the aforementioned linker, the albumin-binding group and a urea-based PSMA binding motif (PSMA-ALB-02, PSMA-ALB-05 and PSMA-ALB-97) were radiolabeled with ${ }^{177} \mathrm{Lu}$ and evaluated against [ ${ }^{177} \mathrm{Lu}$ ]Lu-PSMA-617 in PC-3 PIP tumor bearing mice with all three ligands showing a high tumor-to-blood ratio but still high kidney uptake. These results were further optimized by the replacement of the 4-( $p$-iodophenyl)butanoic acid moiety with ( $p$-tolyl)butanoic acid [153], as the latter demonstrated a reduced albuminbinding affinity [147]. The most promising candidate PSMA-ALB-56 was compared against PSMA-617 in a therapy study of PC-3 PIP tumor bearing mice. $\left[{ }^{177} \mathrm{Lu}\right] \mathrm{Lu}-\mathrm{PSMA}-\mathrm{ALB}-56$ showed a better median survival time of the treated mice than $\left[{ }^{177} \mathrm{Lu}\right] \mathrm{Lu}-\mathrm{PSMA}-617$ when the same activity was applied (5 MBq/mouse), with $4 / 6$ of the $\left[{ }^{177} \mathrm{Lu}\right] \mathrm{Lu}-\mathrm{PSMA}-\mathrm{ALB}-$ 56-treated mice surviving the study. The use of 2-PMPA improved the tumor-to-kidney ratio by reducing kidney uptake of ${ }^{177} \mathrm{Lu}$ ]Lu-PSMA-ALB-56 [154]. In a recently published clinical study, ten patients with metastatic castration resistant prostate cancer (mCRPC) received [ $\left.{ }^{177} \mathrm{Lu}\right] \mathrm{Lu}-\mathrm{PSMA}-\mathrm{ALB}-56$ endoradiotherapy with a higher absorbed dose in tumor lesions and similar salivary gland-uptake compared to PSMA-617 and PSMA I\&T [155]. Nevertheless, kidney and red marrow uptake in these patients remains high, this demands further preclinical optimization of albumin-binding PSMA radioligands (e.g., upon utilization of ibuprofen as an albumin-binding entity) [156-158].

\section{2. $P S M A+G R P r$}

Apart from PSMA, gastrin-releasing peptide receptors (GRPr) are frequently highly expressed in PCa tumors. The bombesin peptide $\left(\mathrm{BBN}=\mathrm{Pyr}^{1}-\mathrm{Gln}^{2}-\mathrm{Arg}^{3}-\mathrm{Leu}^{4}-\mathrm{Gly}^{5}-\mathrm{Asn}^{6}{ }^{6}\right.$ $\mathrm{Gln}^{7}-\mathrm{Trp}^{8}-\mathrm{Ala}^{9}-\mathrm{Val}^{10}-\mathrm{Gly}^{11}-\mathrm{His}^{12}{ }^{12} \mathrm{Leu}^{13}-\mathrm{Met}^{14}-\mathrm{NH}_{2}$ ) is considered a potent agonist for GRPr, while over the years several BBN analogs (either agonists or antagonists of GRPr) have been radiolabeled and evaluated for potential application in Nuclear Medicine [159,160]. The expression of both receptors in tumors is heterogeneous [161], a fact that could potentially result in reduced image quality or false-negative results. A recent 
preclinical study, which evaluated retrospectively frozen prostatectomy samples $(n=20)$ with tissular microimaging using [ $\left.{ }^{111} \mathrm{In}\right]$ In-PSMA-617 and the GRPr antagonist [ $\left.{ }^{111} \mathrm{In}\right] \mathrm{In}$ RM2 ([ $\left.{ }^{111} \mathrm{In}\right]$ In-DOTA-4-amino-1-carboxymethyl-piperidine-D-Phe ${ }^{6}-\mathrm{Gln}^{7}-\mathrm{Trp}^{8}$-Ala ${ }^{9}-\mathrm{Val}^{10}$ $\mathrm{Gly}^{11}$-His ${ }^{12}-\mathrm{Sta}^{13}-\mathrm{Leu}^{14}-\mathrm{NH}_{2}$ ), showed that for [ $\left.{ }^{111} \mathrm{In}\right] \mathrm{In}-\mathrm{PSMA}-617$ the binding was high and independent of the metastatic risk $(p=0.665)$, Gleason score $(p=0.555)$, or PSA value $(p=0.404)$, while $\left[{ }^{111} \mathrm{In}\right] \mathrm{In}-\mathrm{RM} 2$ exhibited a significantly higher binding in the low metastatic risk group $(p=0.046)$, in the low PSA value group $(p=0.001)$, and in samples with Gleason 6 score $(p=0.006)$ [162]. A limited number of patients have been screened with a PSMAtargeting imaging agent ([ $\left.{ }^{68} \mathrm{Ga}\right] \mathrm{Ga}-\mathrm{PSMA}-11$ or $\left.\left[{ }^{18} \mathrm{~F}\right] \mathrm{DCFPyL}\right)$ and the GRPr antagonist $\left[{ }^{68} \mathrm{Ga}\right] \mathrm{Ga}-\mathrm{RM} 2$ [163-167] resulting rather in a complementing than in a competing approach of PSMA vs. GRPr imaging [165,168].

However, in order to overcome this limitation, and increase specificity and sensitivity of the imaging method, the heterodimers approach has been described for a combination of various targets $[169,170]$. Specifically, heterodimers (Hd) targeting PSMA/GRPr have been recently reviewed by Liolios et al. [171]. The first reported heterodimer targeting both PSMA and GRPr consisted of the acyclic chelator HBED-CC, which was linked to either side via its two carboxylic groups not participating at the complexation of the radiometal with the Lys-CO-Glu-OH PSMA binding motif and the GRPr agonist $\mathrm{H}_{2} \mathrm{~N}-\mathrm{PEG}_{2}-\left[D-\mathrm{Tyr}^{6}{ }^{\text {, beta-Ala }}{ }^{11}, \mathrm{Thi}^{13}{ }^{13} \mathrm{Nle}^{14}\right) \mathrm{BN}(6-14)$ [172]. The BBN analog, in this case, was structurally relevant to $\left[{ }^{68} \mathrm{Ga}\right] \mathrm{GaBZH}_{3}\left(\mathrm{DOTA}-\mathrm{PEG}_{2}-\left[D\right.\right.$-tyr ${ }^{6}$, beta-Ala ${ }^{11}$, $\left.\mathrm{Thi}^{13}, \mathrm{Nle}^{14}\right]$ $\mathrm{BN}(6-14))$, which contained a modified BBN sequence, resistant to peptidases, and which has been clinically tested $[173,174]$. The heterodimer Glu-urea-Lys(Ahx)-HBED-CC-BZH3 (Hd-1) showed affinity values comparable to the monomers (PSMA IC $50=25 \pm 5.4 \mathrm{nM}$, GRPr $\mathrm{IC}_{50}=9.0 \pm 1.8 \mathrm{nM}$ ) during in vitro testing in PC-3 (GRPr-positive, androgen independent) and LNCaP (PSMA-positive, androgen depended) cells. Specific cell-binding (either surface bound or internalized) for the ${ }^{68} \mathrm{Ga}$ labeled heterodimer was similar to the control ${ }^{68} \mathrm{Ga}$-monomers, while tumor uptake in LNCaP and AR42J (GRPr positive) xenografts were $5.44 \pm 1.54 \% \mathrm{ID} / \mathrm{g}$ and $3.34 \pm 1.05 \% \mathrm{ID} / \mathrm{g}$, respectively at $1 \mathrm{~h}$ p.i. Tumors were clearly visible during micro-PET imaging ( $1 \mathrm{~h}$ p.i.), however, a high kidney uptake was noted $(110.46 \pm 8.80 \% \mathrm{ID} / \mathrm{g}, 1 \mathrm{~h}$, p.i.), which was minimized during PSMA block $(16.04 \pm 3.94 \%$ ID $/ g)$, but remained unaffected during GRPr block (109.52 $\pm 34.52 \%$ ID/g) clearly indicating the role of PSMA receptors regarding kidney accumulation. This heterodimer was improved to reduce kidney uptake by the addition of so-called $(\mathrm{HE})_{\mathrm{n}}(n=1-3)$ amino acid spacers between the HBED-CC chelator and the PSMA pharmacophore [138]. The new heterodimers $\left(\mathrm{HE}_{\mathrm{n}}\right.$, where $\left.n=0, \mathrm{Hd}-\mathbf{2}, n=1, \mathrm{Hd}-3, n=2, \mathrm{Hd}-4, n=3, \mathrm{Hd}-5\right)$, when tested in vitro they showed high affinity in all cell lines tested: PC-3 $\left(\mathrm{IC}_{50}=4.40\right.$ to $7.72 \mathrm{nM}), \mathrm{AR} 42 \mathrm{~J}\left(\mathrm{IC}_{50}=2.58\right.$ to $\left.5.06 \mathrm{nM}\right)$ and $\mathrm{LNCaP}\left(\mathrm{IC}_{50}=17.4\right.$ to $\left.42.4 \mathrm{nM}\right)$, which were comparable to the respective monomers for each case (PC-3, $3.65 \mathrm{nM}$, AR42J, 1.29 nM, LNCaP $7.5 \mathrm{nM}$ ). During the in vivo experiments in mice with PC-3 ad LNCaP xenografts the $\mathrm{HE}_{2}$ spacer in addition to the reduction of kidney uptake, also managed to increase tumor uptake for both xenografts (Table 3).

Bandari et al. synthesized and radiolabeled with the PET radionuclide ${ }^{64} \mathrm{Cu}$, the heterodimer: DUPA-6-Ahx-( $\left.{ }^{64} \mathrm{Cu}-\mathrm{NODAGA}\right)-5-\mathrm{Ava}-\mathrm{BBN}(7-14) \mathrm{NH}_{2}$ [175]. The heterodimer (Hd-6) was evaluated in vitro in PC-3 and LNCaP cells, where it showed high affinity (PC-3: $\mathrm{IC}_{50}=11.1 \pm 0.46 \mathrm{nM}$; LNCaP: $\mathrm{IC}_{50}=1.16 \pm 1.35 \mathrm{nM}$ ), while during in vivo MicroPET scintigraphy the xenografted PC-3 and LNCaP tumors were clearly visible at $18 \mathrm{~h}$ p.i. Bandari et al. also synthesized the heterodimer [DUPA-6-Ahx-Lys(DOTA)-6-Ahx-RM2] using the antagonist BN peptide (BBN ANT) sequence of RM2 (BBN ANT = D-Phe ${ }^{6}-\mathrm{Gln}^{7}$ $\operatorname{Trp}^{8}-\mathrm{Ala}^{9}-\mathrm{Val}^{10}-\mathrm{Gly}^{11}$-His $\left.{ }^{12}-\mathrm{Sta}^{13}-\mathrm{Leu}^{14}-\mathrm{NH}_{2}\right)(\mathrm{Hd}-7)$, which was labeled with ${ }^{68} \mathrm{Ga},{ }^{111} \mathrm{In}$, or ${ }^{177} \mathrm{Lu}$ for theranostic applications [176]. In a later study and based on this structure, Bandari et al. synthesized and evaluated several heterodimeric ligands testing different spacer groups in addition to 6-Ahx connecting the BBN peptide with the chelator DO3A (DUPA-6Ahx-[DO3A]-X-BBN ANT, where DO3A = 1,4,7,10-tetraazacyclododecane-1,4,7-triacetic acid and $X=5$-aminovaleric acid, 5-Ava; 6- aminohexanoic acid, 6-Ahx; 8-aminooctanoic 
acid, 8-Aoc; and para-aminobenzoic acid, AMBA). In vitro testing revealed low $\mathrm{IC}_{50}$ values for PC-3 (4-7 nM), and LNCaP cells (10-16 nM), both before and after metalation with ${ }^{\text {nat } I n}$ and ${ }^{\text {nat }} \mathrm{Lu}$ [177]. Among the different candidates, the heterodimer DUPA-6Ahx-[DO3A]-8-Aoc -BBN ANT (Hd-8) was selected as the optimal candidate for further in vivo testing with PC-3 and LNCaP xenografts. The selection criterion was its higher accumulation in the pancreas $(5.45 \pm 0.47 \%$ ID $/ g, 1 \mathrm{~h}$ p.i.) during biodistribution studies in normal mice, which clearly indicated GRPr targeting since the normal pancreas is known to overexpress GRPr receptors. The selected heterodimer after radiolabeling with ${ }^{111}$ In and ${ }^{177} \mathrm{Lu}$ presented high stability, both in PBS and in human serum after $4 \mathrm{~h}$ of incubation (at RT), while minor radiolytic degradation was observed at the $24 \mathrm{~h}$. In vivo biodistribution experiments in mice carrying PC-3 or PC-3 PIP xenografts showed rapid elimination (85\% of the injected dose, $4 \mathrm{~h}$ p.i.) of each tracer $\left({ }^{111} \mathrm{In}\right.$ or $\left.{ }^{177} \mathrm{Lu}\right)$ from the bloodstream with excretion profiles being primarily via the renal-urinary pathway. Kidney uptake was also high ranging from $8.90 \pm 1.40 \% \mathrm{ID} / \mathrm{g}$ to $32.2 \pm 28.8 \% \mathrm{ID} / \mathrm{g}$ (until $4 \mathrm{~h}$ p.i.), which was also expected considering PSMA expression in this organ. Tracer uptake in xenografted tumors ranged from $4.74 \pm 0.90$ to $7.51 \pm 2.61 \% \mathrm{ID} / \mathrm{g}$, with the highest values observed at $1 \mathrm{~h}$ p.i. and gradually decaying thereafter. Higher tumor values were observed for the ${ }^{177} \mathrm{Lu}$ labeled compound in both xenografts, which according to the authors was due to the presence of more nonradioactive [DUPA-6-Ahx-([ $\left.\left.\left.{ }^{\text {nat }} \mathrm{Lu}\right]-\mathrm{Lu}-\mathrm{DO} 3 \mathrm{~A}\right)-8-\mathrm{Aoc}-\mathrm{BBN} \mathrm{ANT}\right]$ in comparison to the ${ }^{111}$ In labeled analog [177]. Possibly, the nonradioactive ligand blocked the clearance route of the radioactive tracer, resulting in higher kidney radioactivity and more importantly in higher circulating amounts of [DUPA-6-Ahx-([ $\left.\left.{ }^{177} \mathrm{Lu}\right]-\mathrm{Lu}-\mathrm{DO} 3 \mathrm{~A}\right)-8$ Aoc-BBN ANT], which eventually was accumulated in the tumors. This hypothesis in combination with the increased radioactivity amounts observed in normal organs during the blocking experiments further noted the importance of high specific activity for such radiopharmaceutical applications and further enhancement of heterodimeric ligands, i.e., with albumin binders.

Mendoza-Figueroa et al. designed a heterodimeric ${ }^{68} \mathrm{Ga}$-labeled radiotracer $\left(\left[{ }^{68} \mathrm{Ga}\right] \mathrm{Ga}-\right.$ iPSMA-BN) (Hd-9) consisting of an iPSMA (Nal-Lys-CO-Glu-OH) and a Lys ${ }^{3}$-Bombesin part linked to a DOTA chelator. When $\left[{ }^{68} \mathrm{Ga}\right] \mathrm{Ga}$-iPSMA-BN was evaluated against the monomers $\left[{ }^{68} \mathrm{Ga}\right] \mathrm{Ga}-\mathrm{iPSMA}$ and $\left[{ }^{68} \mathrm{Ga}\right] \mathrm{Ga}-\mathrm{BN}$ in vitro and in vivo in LNCaP cells and PC-3 cells, it showed superiority against each monomer $\left[{ }^{68} \mathrm{Ga}\right] \mathrm{Ga}-\mathrm{iPSMA}$ and $\left[{ }^{68} \mathrm{Ga}\right] \mathrm{Ga}-\mathrm{BN}$, in both cell lines and animal models (Table 3) [178]. The same group has published a study where they evaluated this heterodimer labeled with ${ }^{177} \mathrm{Lu}$ [179]. The heterodimer showed a significant decrease in LNCaP (10.15\%) and PC-3 (40.10\% at $48 \mathrm{~h}$ ) viability in vitro, and a high LNCaP and PC-3 tumor uptake in ex vivo biodistributions (5.21 and 3.21\% ID/g at $96 \mathrm{~h}$, respectively), and Micro-SPECT/CT imaging studies (SUV max of $1.93 \pm 0.30$ and $1.76 \pm 0.10$ in LNCaP and PC-3, respectively), possibly influenced by the heterobivalent effect. More recently, biokinetics and dosimetry data have been obtained for [ $\left.{ }^{68} \mathrm{Ga}\right] \mathrm{Ga}-$ iPSMA-BN in a study of four healthy patients showing specific uptake in the pancreas (GRPr expressing) and salivary glands (PSMA expressing) [180].

Mitran et al. synthesized the heterodimer NOTA-DUPA-RM26 (BQ7800) consisting of (Hd-10) (DUPA = 2-[3-(1,3-dicarboxypropyl)-ureido]pentanedioic acid) consisting of a Glu-CO-Glu PSMA-binding motif and the GRPr antagonist RM26 (D-Phe-Gln-Trp-Ala-ValGly-His-Sta-Leu-NH2). Both binding motifs were coupled via glutamic acid and contain NOTA as a chelator for radiolabeling with either ${ }^{68} \mathrm{Ga}$ or ${ }^{111} \mathrm{In}$ [181]. In vitro preclinical evaluation resulted in high affinity for GRPr $\left(\mathrm{IC}_{50}=4.0 \pm 1.0 \mathrm{nM}\right)$ and rather low for PSMA $\left(\mathrm{IC}_{50}=824 \pm 230 \mathrm{nM}\right)$. However, at $1 \mathrm{~h}$ p.i., tumor uptake in PC-3 PIP xenografts for $\left[{ }^{111} \mathrm{In}\right] \mathrm{In}-\mathrm{BQ7800}(12 \pm 2 \% \mathrm{ID} / \mathrm{g})$ and $\left[{ }^{68} \mathrm{Ga}\right] \mathrm{Ga}-\mathrm{BQ7800}(8 \pm 2 \% \mathrm{ID} / \mathrm{g})$ was higher than the one in normal organs and was decreased thereafter. However, kidney uptake was similar to the tumor uptake, while increased uptake was observed in organs expressing GRPr receptors. Attempts to improve the PSMA-specific tumor uptake were made by incorporating phenylalanine into the linker of the PSMA-binding motif and shortening of the PEG linker (BQ7812). The tumor uptake of $\left[{ }^{111} \mathrm{In}\right] \mathrm{In}-\mathrm{BQ7812}$ (Hd-11) was doubled 
compared to [111 In]In-BQ7800, but the modifications also led to a three-fold increase of uptake in the kidneys [182].

Finally, three additional bispecific heterodimers based on RM2 peptide sequence $(D$ $\mathrm{Phe}^{6}-\mathrm{Gln}^{7}-\mathrm{Trp}^{8}-\mathrm{Ala}^{9}-\mathrm{Val}^{10}-\mathrm{Gly}^{11}-\mathrm{His}^{12}-\mathrm{Sta}^{13}-\mathrm{Leu}^{14}-\mathrm{NH}_{2}$ ) and PSMA-617 are reported [183]. The two pharmacophores were linked via the spacer: $\mathrm{X}$-triazolyl-Tyr- $-\mathrm{PEG}_{2}$, where $\mathrm{X}=0$ (Hd-12), $\mathrm{PEG}_{2}$ (Hd-13), $\left(\mathrm{CH}_{2}\right)_{8}$ (Hd-14). The resulting heterodimers were radio-iodinated and evaluated in vitro for binding specificity, cellular retention, and affinity. In vivo specificity and tumor uptake for all heterodimers was studied in PC-3 and LNCaP xenografts (Table 3), while [ $\left.{ }^{125} \mathrm{I}\right] \mathrm{I}-\mathrm{Hd}-\mathbf{1 3}$ was also evaluated in PC-3 PIP xenografts where it showed high tumor accumulation ( $30-35 \% \mathrm{ID} / \mathrm{g}$ at $3 \mathrm{~h}$ p.i.). However, this was followed by high kidney radioactivity values like the first heterodimer: $\left[{ }^{68} \mathrm{Ga}\right] \mathrm{Ga}-\mathrm{Hd}-1$.

Table 3. Heterodimers targeting PSMA/GRPr, tumor uptake (1 h p.i.) expressed as (\% ID/g) in PC-3, AR42J, LNCaP or PC-3 PIP xenografts (Mean value \pm Std).

\begin{tabular}{|c|c|c|c|c|c|}
\hline \multirow{2}{*}{ Heterodimer } & \multicolumn{4}{|c|}{ Tumor Uptake (1 h p.i.; ${ }^{\&} 24$ h p.i., ${ }^{\#} 96$ h p.i.) (\% ID/g \pm SD) } & \multirow{2}{*}{ Ref. } \\
\hline & PC-3 & AR42J & LNCaP & PC-3 PIP & \\
\hline$\left[{ }^{68} \mathrm{Ga}\right] \mathrm{Ga}-\mathrm{Hd}-1$ & - & $3.34 \pm 1.04$ & $5.44 \pm 1.54$ & - & [172] \\
\hline$\left[{ }^{68} \mathrm{Ga}\right] \mathrm{Ga}-\mathrm{Hd}-2$ & $0.84 \pm 0.18$ & - & $2.38 \pm 0.05$ & - & \\
\hline$\left[{ }^{68} \mathrm{Ga}\right] \mathrm{Ga}-\mathrm{Hd}-3$ & $2.67 \pm 1.25$ & - & $2.41 \pm 1.24$ & - & \\
\hline$\left[{ }^{68} \mathrm{Ga}\right] \mathrm{Ga}-\mathrm{Hd}-4$ & $2.23 \pm 0.27$ & - & $10.66 \pm 4.19$ & - & [138] \\
\hline$\left[{ }^{68} \mathrm{Ga}\right] \mathrm{Ga}-\mathrm{Hd}-5$ & $1.66 \pm 0.41$ & - & $3.22 \pm 0.22$ & - & \\
\hline$\left[{ }^{64} \mathrm{Cu}\right] \mathrm{Cu}-\mathrm{Hd}-6$ & - & - & - & - & [175] \\
\hline $\mathrm{Hd}-7$ & - & - & - & - & [176] \\
\hline ([111 In]In-Hd-8 & $4.74 \pm 0.90$ & - & - & $5.38 \pm 1.07$ & [177] \\
\hline$\left[{ }^{177} \mathrm{Lu}\right] \mathrm{Lu}-\mathrm{Hd}-8$ & $7.51 \pm 2.61$ & - & - & $7.37 \pm 2.89$ & [177] \\
\hline$\left[{ }^{68} \mathrm{Ga}\right] \mathrm{Ga}-\mathrm{Hd}-9$ & $7.39 \pm 0.65$ & - & $13.67 \pm 3.88$ & - & [178] \\
\hline$\left[{ }^{177} \mathrm{Lu}\right] \mathrm{Lu}-\mathrm{Hd}-9$ & $\begin{array}{c}1.76 \pm 0.10^{\&} \\
\sim 3.21^{\#}\end{array}$ & - & $\begin{array}{c}1.93 \pm 0.3^{\&} \\
\sim 5.21^{\#}\end{array}$ & - & [179] \\
\hline [111 In]In-Hd-10 & - & - & - & $12.0 \pm 2.0$ & [181] \\
\hline$\left[{ }^{68} \mathrm{Ga}\right] \mathrm{Ga}-\mathrm{Hd}-10$ & - & - & - & $8.0 \pm 2.0$ & [181] \\
\hline$\left[{ }^{111}\right.$ In]In-Hd-11 & - & - & - & $16.10 \pm 2.96$ & [182] \\
\hline$\left[{ }^{125} \mathrm{I}\right] \mathrm{I}-\mathrm{Hd}-12$ & $3.0 \pm 0.3$ & & $11.0 \pm 3.0$ & & \\
\hline$\left.{ }^{125} \mathrm{I}\right] \mathrm{I}-\mathrm{Hd}-13$ & $4.3 \pm 0.6$ & & $10.0 \pm 3.0$ & & [183] \\
\hline$\left[{ }^{125} \mathrm{I}\right] \mathrm{I}-\mathrm{Hd}-14$ & $2.2 \pm 0.6$ & & $3.0 \pm 2.0$ & $\sim 21.0$ & \\
\hline
\end{tabular}

\subsection{PSMA + Integrin $\alpha_{v} \beta_{3}$}

Two heterobivalent imaging agents targeting PSMA and integrin- $\alpha_{\mathrm{v}} \beta_{3}$ surface markers, both overexpressed in certain tumor epithelium and/or neovasculature were synthesized and evaluated by Shallal et al. [184]. Integrins $\alpha_{v} \beta_{3}$ are considered an ideal target for the development of radioligands, since they are overexpressed on tumor vasculature due to angiogenesis, and on the cell membrane in various tumors, i.e., ovarian cancer, neuroblastoma, breast cancer and melanoma [185]. The tripeptide RGD (arginine-glycineaspartic) amino acid sequence and its cyclic RGD (cRGD) analogs specifically bind to the integrin $\alpha_{v} \beta_{3}$ receptor and thus have provided the platform for the development of various radioligands [185]. The heterodimers consisted of Lys-CO-Glu-OH PSMA binding motif connected to the Lys of a cyclic cRGDfK peptide (cyclo-(Arg-Gly-Asp-D-Phe-Lys)) and coupled either to the DOTA chelator for radiolabeling (Hd-15) or to the dye IRDye800CW (Hd-16). In vitro testing in PC-3 PIP and U87-MG cells and in isolated proteins showed low affinity with high $\mathrm{IC}_{50}$ values for the both PSMA and $\alpha_{\mathrm{v}} \beta_{3}$ receptors, i.e., Hd-15: PC-3 PIP, IC $50=479 \mathrm{nM}$, U87-MG, IC $50=1536 \mathrm{nM}$, Hd-16: integrin $\alpha_{\mathrm{v}} \beta_{3} \mathrm{IC}_{50}=90 \mathrm{nM}$. In vivo, optical imaging and ex vivo biodistribution studies for Hd-16 showed specific tumor uptake for PC-3 PIP tumors expressing PSMA, and U87-MG tumors expressing integrin $\alpha_{\mathrm{v}} \beta_{3}$. Tumor uptake was dose-dependent, and even at the lowest dose $(0.5 \mathrm{nmol})$ the tumors were clearly visible. However, this study did not include a metalated or a radiolabeled version of $\mathrm{Hd}-\mathbf{1 5}$ [184]. 


\section{Future Methods and Concepts for PSMA Inhibitor Radiolabeling}

The fluoroglycosylation method by Maschauer et al. [186] has been applied to obtain 2- $\left[{ }^{18} \mathrm{~F}\right]$ FGlc-PSMA and $6-\left[{ }^{18} \mathrm{~F}\right]$ FGlc-PSMA with the latter example highlighting a 10-fold decrease in kidney uptake in PC-3 PIP tumor bearing mice compared to 2- $\left[{ }^{18} \mathrm{~F}\right] \mathrm{FGlc}$-PSMA and $\left[{ }^{68} \mathrm{Ga}\right] \mathrm{Ga}-\mathrm{PSMA}-11$ [187].

Greifenstein et al. used a squaric acid (SA) moiety to link the Glu-urea-Lys PSMA binding motif with the chelator [188]. Out of three SA-PSMA inhibitors with different chelators, DOTAGA.SA.PSMA emerged as a lead structure to be compared against ${ }^{68} \mathrm{Ga}-$ radiolabeled PSMA-617 and PSMA-11. $\left[{ }^{68} \mathrm{Ga}\right] \mathrm{Ga}-D O T A G A . S A . P S M A$ showed tumor uptake in LNCaP tumor bearing mice comparable with [ $\left.{ }^{68} \mathrm{Ga}\right] \mathrm{Ga}-\mathrm{PSMA}-617$ and lower than $\left[{ }^{68} \mathrm{Ga}\right]$ Ga-PSMA-11 (5.6 $\pm 0.3 \% \mathrm{ID} / \mathrm{g}$ vs. $6.5 \pm 1.0 \% \mathrm{ID} / \mathrm{g}$ vs. $\left.12.8 \pm 1.5 \% \mathrm{ID} / \mathrm{g}\right)$, but significantly lower uptake in kidneys $(3.2 \pm 0.5 \% \mathrm{ID} / \mathrm{g}$ vs. $16.2 \pm 5.7 \% \mathrm{ID} / \mathrm{g}$ vs. $210.8 \pm 8.1 \% \mathrm{ID} / \mathrm{g}$ ) and in other organs (60 $\mathrm{min}$ p.i.) showing thus a potential as therapeutic agent [189].

The isotopic exchange chemistry for the fluorine isotopes ${ }^{19} \mathrm{~F} /{ }^{18} \mathrm{~F}$ has been described by Schirrmacher et al. using silicon-fluoride-acceptor (SiFA) building blocks [190]. This concept has been adopted for PSMA inhibitors, which also introduce a chelator into the molecule in close proximity to the SiFA motif in order to increase hydrophilicity [191]. This permits the radiolabeling of the molecule with either ${ }^{18} \mathrm{~F}$ at the SiFA building block or with a radiometal of choice (e.g., ${ }^{68} \mathrm{Ga},{ }^{177} \mathrm{Lu},{ }^{225} \mathrm{Ac}$ ) at the chelator while the moiety not used for radiolabeling is occupied with the non-radioactive ${ }^{19} \mathrm{~F}$ or metal, which has been called by the authors radiohybrid PSMA (rhPSMA) inhibitors. Wurzer et al. developed a series of these rhPSMA inhibitors, with rh-PSMA-7 being the most promising candidate being radiolabeled with ${ }^{18} \mathrm{~F}$, bearing ${ }^{\text {nat }} \mathrm{Ga}$ within the chelator and being clinically evaluated in a number of patients with primary and biochemical recurrence of PCa [191-194]. Further improvement of rh-PSMA-7 has been achieved by investigation of its four stereoisomers and their influence on pharmacokinetics [83]. The resulting lead candidate $\left[{ }^{18} \mathrm{~F}\right] \mathrm{Ga}-\mathrm{rh}-\mathrm{PSMA}-$ 7.3 showed the highest tumor accumulation and low uptake in non-target tissues. This was confirmed in healthy volunteers determining biodistribution and radiation dosimetry data (NCT03995888) and in a larger cohort of patients [84,195-197]. The molar activity of $\left[{ }^{18} \mathrm{~F}\right]$ Ga-rh-PSMA-7.3 had a minor influence on the biodistribution $[198,199]$. Three clinical trials using $\left[{ }^{18} \mathrm{~F}\right] \mathrm{Ga}$-rh-PSMA-7.3 are either ongoing or will commence in the near future (NCT04978675/NCT04186819/NCT04186845). The therapeutic counterpart $\left[{ }^{177} \mathrm{Lu}\right] \mathrm{Lu}-\mathrm{rhPSMA}-7.3$ showed a higher anti-tumor effect and longer median survival in C42 xenograft-bearings SCIDS than [ ${ }^{177} \mathrm{Lu}$ ]Lu-PSMA I\&T [85] followed by a pre-therapeutic dosimetry study in six mCRPC patients confirming the preclinical results [86].

Another approach of isotopic exchange has been reported for eight PSMA inhibitors by substituting ${ }^{19} \mathrm{~F}$ with ${ }^{18} \mathrm{~F}$ at a trifluoroborate group [200]. This concept has been extended to the radiohybrid ligand DOTA-AMBF 3 -PSMA [201]. The PSMA-617 pharmacophore was used as a starting point, then a lysine-trifluoroborate moiety was introduced and linked to a DOTA-chelator allowing radiolabeling with either ${ }^{18} \mathrm{~F}$ or a radiometal. DOTA-AMBF 3 -PSMA radiolabeled with ${ }^{18} \mathrm{~F} /$ free, ${ }^{18} \mathrm{~F} /{ }^{\text {nat }} \mathrm{Cu},{ }^{\text {nat }} \mathrm{F} /{ }^{64} \mathrm{Cu}$ and ${ }^{\text {nat }} \mathrm{F} /{ }^{177} \mathrm{Lu}$ was preclinically evaluated in LNCaP xenografts with tumor uptake $>10 \% \mathrm{ID} / \mathrm{g}$ for all radiotracers. $\left[{ }^{64} \mathrm{Cu}\right] \mathrm{Cu}-\mathrm{DOTA}-\mathrm{AMBF}_{3}-\mathrm{PSMA}$ showed increased liver uptake, most likely due to transchelation of ${ }^{64} \mathrm{Cu}$ from the DOTA-chelator which has also been observed for $\left[{ }^{64} \mathrm{Cu}\right] \mathrm{Cu}$-DOTA and $\left[{ }^{64} \mathrm{Cu}\right] \mathrm{Cu}-\mathrm{PSMA}-617[202,203]$. An increased liver uptake was seen in patients scanned with $\left[{ }^{64} \mathrm{Cu}\right] \mathrm{Cu}-\mathrm{PSMA}-6172 \mathrm{~h}$ and $22 \mathrm{~h}$ post injection as well as in a biodistribution and radiation dosimetry study using $\left[{ }^{64} \mathrm{Cu}\right] \mathrm{CuCl}_{2}[204,205]$.

\section{Potential Radionuclides for the Future Use of PSMA Inhibitors}

While radionuclides like ${ }^{68} \mathrm{Ga},{ }^{18} \mathrm{~F}$, or ${ }^{177} \mathrm{Lu}$ have become a sort of routine in the use of radiolabeled PSMA inhibitors, other radionuclides are gaining attention due to their specific properties [206-208]. For example, ${ }^{225}$ Ac can play a pivotal role in targeted alpha therapy (TAT) of prostate cancer $[48,51,78,209-215]$, but additional preclinical studies and 
prospective clinical trials need to be performed to secure its safety and efficacy [216-221]. The importance of ${ }^{225}$ Ac-labeled radiopharmaceuticals is affirmed by efforts to establish GMP-compliant procedures for production and quality control [222-226]. Regulatory aspects on the supply of radionuclides for routine clinical application represent a hurdle that needs to be considered for the translation of new radiopharmaceuticals [227,228].

\section{1. ${ }^{211}$ Astatine}

${ }^{211}$ At is a radiohalogen with a half-life of $7.2 \mathrm{~h}$ suitable for TAT using small molecules. Several PSMA radioligands have been radiolabeled with ${ }^{211} \mathrm{At}$ and indicated improved survival rates in PC-3 PIP PSMA-positive tumor bearing mice [229,230]. Although the inclusion of albumin binding moieties increases blood retention and reduces kidney uptake [149], dehalogenation and nephrotoxicity have been the limiting factors for clinical translation. The latest development ${ }^{211} \mathrm{At}-3-\mathrm{Lu}$ [230] showed improved toxicity data for kidney uptake and reduced off-target uptake in organs like the stomach and salivary glands. The infrastructure for the production of ${ }^{211}$ At-labeled radiopharmaceuticals is complex though, efforts are made to make them more widely available [231,232], such as the NOAR COST action, which has the goal to create a European Network for Optimized Astatine labeled Radiopharmaceuticals.

\section{2. ${ }^{64 / 67}$ Copper}

The Donnelly group investigated the bivalent PSMA inhibitor Sar-bisPSMA with the matched pair ${ }^{64} \mathrm{Cu} /{ }^{67} \mathrm{Cu}$ against $\left[{ }^{68} \mathrm{Ga}\right] \mathrm{Ga}-\mathrm{PSMA}-11$ and $\left[{ }^{177} \mathrm{Lu}\right] \mathrm{Lu}-\mathrm{PSMA}$ I\&T respectively in a LNCaP xenograft model $[233,234]$. Sar-bisPSMA consists of a sarcophagine based chelator covalently linked to two lysine-ureido-glutamate functional groups, which can be radiolabeled with copper isotopes at room temperature. $\left[{ }^{64} \mathrm{Cu}\right] \mathrm{Cu}-\mathrm{Sar}$-bisPSMA showed higher tumor uptake than $\left[{ }^{68} \mathrm{Ga}\right] \mathrm{Ga}-\mathrm{PSMA}-111 \mathrm{~h}$ after injection $(9 \pm 1 \% \mathrm{IA} / \mathrm{g}$ vs. $5 \pm 1 \%$ IA/g). The dose-dependent tumor growth inhibition of $\left[{ }^{67} \mathrm{Cu}\right] \mathrm{Cu}$-Sar-bisPSMA was comparable to [ $\left.{ }^{177} \mathrm{Lu}\right] \mathrm{Lu}-\mathrm{PSMA}$ I\&T (5 MBq: 58 vs. $65 \%$, $30 \mathrm{MBq}$ : 109 vs. $107 \%$ against vehicle control). The longer half-life of $\left[{ }^{64} \mathrm{Cu}\right] \mathrm{Cu}$-Sar-bisPSMA allows prospective dosimetry for the use of [ $\left.{ }^{67} \mathrm{Cu}\right] \mathrm{Cu}$-Sar-bisPSMA. Two clinical trials using $\left[{ }^{64} \mathrm{Cu}\right] \mathrm{Cu}$-Sar-bisPSMA and $\left[{ }^{67} \mathrm{Cu}\right] \mathrm{Cu}$-Sar-bisPSMA have been started in 2021 (NCT04839367/NCT04868604).

Kelly et al. similarly used a sarcophagine chelator (MeCOSar) conjugated to $\mathrm{N}^{\varepsilon}$-(2(4-iodophenyl)acetyl)lysine as albumin binding group and a PSMA binding motif (RPS085) [235]. Uptake of [ $\left.{ }^{64} \mathrm{Cu}\right] \mathrm{Cu}-\mathrm{RPS}-085$ in LNCaP tumor bearing mice was constant for the tumor $(4$ h p.i.: $12.9 \pm 1.4 \%$ ID/g, 24 h p.i.: $8.3 \pm 0.8 \%$ ID/g, 48 h p.i.: $9.8 \pm 1.3 \%$ ID/g), while the uptake in the kidneys decreased over time leading to an increased tumorto-kidney ratio of $6.1 \pm 0.848 \mathrm{~h}$ p.i. The biodistribution was similar when RPS-085 was radiolabeled with ${ }^{67} \mathrm{Cu}$, with a tumor-to-kidney ratio of $3.0 \pm 0.5,96 \mathrm{~h}$ p.i.

\section{3. ${ }^{203 / 212}$ Lead}

${ }^{203} \mathrm{~Pb}$ and ${ }^{212} \mathrm{~Pb}$ form an ideal theranostic pair for SPECT imaging and TAT with half-lives of $51.9 \mathrm{~h}$ and $10.6 \mathrm{~h}$ respectively. The production methods for $203 / 212 \mathrm{~Pb}$ have been improved making them available for potential clinical application [236]. Dos Santos et al. developed four PSMA inhibitors (CA008, CA009, CA011 and CA012) with p-SCN-Bn-TCMC and DO3AM chelators bearing the PSMA-617 binding motif and linker structure [237]. The best ligand PSMA-CA012 radiolabeled with ${ }^{203} \mathrm{~Pb}$ showed similar tumor uptake like [ ${ }^{68} \mathrm{Ga}$ ]Ga-PSMA-617 in PSMA-positive C4-2 tumor-bearing mice $(8.4 \pm 3.7 \%$ ID $/ g$ vs. $8.5 \pm 4.1 \%$ ID/g). Two patients have been studied first-in-human with [ $\left.{ }^{203} \mathrm{~Pb}\right] \mathrm{Pb}-\mathrm{PSMA}-\mathrm{CA} 012$ and safety dosimetry estimates for [ $\left.{ }^{203} \mathrm{~Pb}\right] \mathrm{Pb}-\mathrm{PSMA}-\mathrm{CA} 012$ and $\left[{ }^{212} \mathrm{~Pb}\right] \mathrm{Pb}$-PSMA-CA012 were determined. Stenberg et al. reported the synthesis of NG-001, which has the same chemical structure as CA009 [238]. [ $\left.{ }^{212} \mathrm{~Pb}\right] \mathrm{Pb}-\mathrm{NG} 001$ was prepared in situ from a ${ }^{224} \mathrm{Ra}$-solution in equilibrium with progeny [239]. [ $\left.{ }^{212} \mathrm{~Pb}\right] \mathrm{Pb}-\mathrm{NG} 001$ was evaluated against $\left[{ }^{212} \mathrm{~Pb}\right] \mathrm{Pb}-\mathrm{PSMA}-617$ in mice bearing C4-2 tumors. While the tumor uptake was comparable 2 h p.i. (17.61 $\pm 6.76 \%$ ID/g vs. $17.93 \pm 2.90 \%$ ID/g), kidney uptake 
was lower for [ $\left.{ }^{212} \mathrm{~Pb}\right] \mathrm{Pb}-\mathrm{NG} 001$ (21.07 $\pm 10.33 \%$ ID/g vs. $52.82 \pm 26.62 \%$ ID/g) [238,239]. Dose-dependent treatment efficiency of [ $\left.{ }^{212} \mathrm{~Pb}\right] \mathrm{Pb}-\mathrm{NG} 001$ was confirmed in multicellular C4-2 spheroids and the corresponding mouse model with no long-term toxicity effects [240]. Apart from DOTA and TCMC, pyridine-based cyclen analogs (DOTA-1Py, DOTA-2Py and DOTA-3Py) [236] may be a better chelator alternative for ${ }^{212} \mathrm{~Pb}$ and its daughter isotopes for avoiding recoil effects [241].

\section{4. ${ }^{149 / 152 / 155 / 161}$ Terbium}

Terbium, also called the "Swiss Army Knife" of Nuclear Medicine with its quadruplet of radioisotopes [242] with suitable properties for imaging with PET $\left({ }^{152} \mathrm{~Tb} /{ }^{149} \mathrm{~Tb}\right)$ and SPECT $\left({ }^{155} \mathrm{~Tb}\right)$ and endoradiotherapy with alpha $\left({ }^{149} \mathrm{~Tb}\right)$ and beta ${ }^{-} /$Auger electrons $\left({ }^{161} \mathrm{~Tb}\right)$, has been investigated by the group at Paul Scherrer Institute (PSI). Terbium radioisotopes have been used in combination with PSMA-617 in PSMA-positive PC-3 PIP tumor cells. $\left[{ }^{152} \mathrm{~Tb}\right] \mathrm{Tb}$-PSMA-617 has been evaluated in vitro and in vivo and successfully applied firstin-human in a patient with metastatic castration-resistant prostate cancer [76]. Suppression of tumor growth has been demonstrated using [ $\left.{ }^{149} \mathrm{~Tb}\right] \mathrm{Tb}$-PSMA-617 in TAT in mice bearing PC-3 PIP tumor cells [243]. In a preclinical study, [ $\left.{ }^{161} \mathrm{~Tb}\right] \mathrm{Tb}-\mathrm{PSMA}-617$ was compared against $\left[{ }^{177} \mathrm{Lu}\right] \mathrm{Lu}-\mathrm{PSMA}-617$ in a PC-3 PIP xenograft model showing the superiority of ${ }^{161} \mathrm{~Tb}$ vs. ${ }^{177} \mathrm{Lu}[244,245]$ opening the way for clinical translation. The additional therapeutic effect of ${ }^{161} \mathrm{~Tb}$ due to Auger electrons was confirmed by a computational approach using a microdosimetry model [246]. However, despite these very promising results, the production of terbium radioisotopes for clinical application remains challenging [247,248].

\section{5. ${ }^{89}$ Zirconium}

Vázquez et al., modified PSMA-617 by replacing DOTA with DFO as chelator making it suitable for radiolabeling with ${ }^{89} \mathrm{Zr}$ [249]. ${ }^{89} \mathrm{Zr}$ is a positron-emitter with a physical halflife of 3.27 days. The aim of this study was to detect low PSMA-expressing lesions which are negative on PSMA PET scans using short-lived radiotracers, such as [ $\left.{ }^{68} \mathrm{Ga}\right] \mathrm{Ga}-\mathrm{PSMA}-11$ and $\left[{ }^{18} \mathrm{~F}\right] J K-P S M A-7$ by increasing the time for internalization of the radioligand. In a LNCaP xenograft model, $24 \mathrm{~h}$ after intravenous injection [ ${ }^{89} \mathrm{Zr}$ ] Zr-PSMA-DFO showed a higher tumor-to-background ratio than $\left[{ }^{68} \mathrm{Ga}\right] \mathrm{Ga}-\mathrm{PSMA}-11$ and $\left[{ }^{18} \mathrm{~F}\right] \mathrm{JK}-\mathrm{PSMA}-7$ after 2 and $4 \mathrm{~h}$. In a small number of patients (8/14) additional lesions were identified with $\left[{ }^{89} \mathrm{Zr}\right] \mathrm{Zr}-\mathrm{PSMA}-\mathrm{DFO}$ after initial scans were negative with $\left[{ }^{68} \mathrm{Ga}\right] \mathrm{Ga}-\mathrm{PSMA}-11$ or $\left[{ }^{18} \mathrm{~F}\right] \mathrm{JK}-$ PSMA-7 [250]. An additional [ ${ }^{89} \mathrm{Zr}$ ]Zr-PSMA-DFO PET scan at later time points might be beneficial for patients with biochemical recurrence and weak PSMA expression in tumor lesions.

Noor et al. [251] conjugated the Lys-ureido-Glu binding motif to the desferrioxamine B squareamide ester derivative $\mathrm{H}_{3}$ DFOSq, leading to two monovalent and two bivalent DFOSq-lysine-ureido-glutamate derivatives with different linker structures to be radiolabeled with ${ }^{89} \mathrm{Zr}$ and ${ }^{68} \mathrm{Ga}$. The bivalent ligands performed superior in LNCaP tumor models compared to the monovalent ligands. The bivalent ligand bearing an aromatic hydrophobic linker $\left(\mathrm{H}_{3} \mathrm{DFO}\right.$-tren-bis(glut-PAMBA-Lys-ureido-Glu)) showed the highest tumor uptake when radiolabeled with ${ }^{89} \mathrm{Zr}$ and ${ }^{68} \mathrm{Ga}$ compared against [ ${ }^{68} \mathrm{Ga}$ ]Ga-PSMA-11 [252] $1 \mathrm{~h}$ after injection (9.33 $\pm 0.33 \%$ IA/g vs. $10.8 \pm 1.3 \%$ IA/g vs. $4.89 \pm 1.34 \%$ IA/g).

\section{Conclusions}

The feasibility of theranostics with PSMA-targeting radiopharmaceuticals has been successfully demonstrated in the last decade, upon their radiolabeling using pairs of radionuclides with suitable properties for imaging with PET or SPECT and endoradiotherapy with alpha and beta ${ }^{-}$/ Auger electrons. Radioguided and fluorescence-guided surgery should be an additional treatment option for PCa patients, in this direction PSMA ligands for radio-/fluorescence-guided surgery and/or targeted photodynamic therapy are being investigated. In order to further improve the efficiency and efficacy of the existing PSMA radioligands for PCa diagnosis and radionuclide therapy several structural modifications 
have been suggested for reducing their uptake in off-target tissues or utilizing multitargeting (i.e., albumin, GRPr and integrin $\alpha_{\mathrm{v}} \beta_{3}$ ). Addressing additional targets like GRPr with one radiotracer could reduce the number of false-negative findings. New radionuclides in combination with PSMA-binding structures are also being explored, but care should be taken on their radiobiological effects, availability for mass production and cost.

Author Contributions: Writing-original draft preparation, O.C.N.; writing-review and editing, O.C.N., K.K., C.L., A.A.-O. All authors have read and agreed to the published version of the manuscript.

Funding: This research received no external funding.

Conflicts of Interest: K.K. is coinventor of PSMA-617, PSMA-914 and PSMA-1007 and derivatives thereof. Moreover, K.K. is member of the scientific advisory board of Telix Pharmaceuticals Ltd. All other authors declare that they have no conflict of interest.

\section{References}

1. Hofman, M.S. Prostate-Specific Membrane Antigen: The Target of the Decade, from Biochemical Recurrence to Widespread Adoption. J. Nucl Med. 2020, 61, 246S-247S. [CrossRef]

2. Czernin, J.; Calais, J. (177)Lu-PSMA617 and the VISION Trial: One of the Greatest Success Stories in the History of Nuclear Medicine. J. Nucl Med. 2021, 62, 1025-1026. [CrossRef]

3. Murphy, D.G.; Sathianathen, N.; Hofman, M.S.; Azad, A.; Lawrentschuk, N. Where to Next for Theranostics in Prostate Cancer? Eur. Urol. Oncol. 2019, 2, 163-165. [CrossRef]

4. Herrmann, K.; Schwaiger, M.; Lewis, J.S.; Solomon, S.B.; McNeil, B.J.; Baumann, M.; Gambhir, S.S.; Hricak, H.; Weissleder, R. Radiotheranostics: A roadmap for future development. Lancet Oncol. 2020, 21, e146-e156. [CrossRef]

5. Hofman, M.S. Bringing VISION to Nuclear Medicine: Accelerating evidence and changing paradigms with theranostics. J. Nucl. Med. 2021. [CrossRef] [PubMed]

6. Fendler, W.P.; Eiber, M.; Beheshti, M.; Bomanji, J.; Ceci, F.; Cho, S.; Giesel, F.; Haberkorn, U.; Hope, T.A.; Kopka, K.; et al. (68)Ga-PSMA PET/CT: Joint EANM and SNMMI procedure guideline for prostate cancer imaging: Version 1.0. Eur. J. Nucl. Med. Mol. Imaging 2017, 44, 1014-1024. [CrossRef] [PubMed]

7. Fanti, S.; Minozzi, S.; Antoch, G.; Banks, I.; Briganti, A.; Carrio, I.; Chiti, A.; Clarke, N.; Eiber, M.; De Bono, J.; et al. Consensus on molecular imaging and theranostics in prostate cancer. Lancet Oncol. 2018, 19, 696-708. [CrossRef]

8. Kratochwil, C.; Fendler, W.P.; Eiber, M.; Baum, R.; Bozkurt, M.F.; Czernin, J.; Delgado Bolton, R.C.; Ezziddin, S.; Forrer, F.; Hicks, R.J.; et al. EANM procedure guidelines for radionuclide therapy with (177)Lu-labelled PSMA-ligands ((177)Lu-PSMA-RLT). Eur. J. Nucl. Med. Mol. Imaging 2019, 46, 2536-2544. [CrossRef] [PubMed]

9. Afshar-Oromieh, A.; Eiber, M.; Fendler, W.; Schmidt, M.; Rahbar, K.; Ahmadzadehfar, H.; Umutlu, L.; Hadaschik, B.; Hakenberg, O.W.; Fornara, P.; et al. PSMA-Liganden-PET/CT in der Diagnostik des Prostatakarzinoms. 2019. Available online: https:/ / www.awmf.org/uploads/tx_szleitlinien/031-0551_S1_PSMA-Liganden-PET-CT-Diagnostik-Prostatakarzinoms_2020 -05.pdf (accessed on 26 October 2021).

10. Vorster, M.; Warwick, J.; Lawal, I.O.; Du Toit, P.; Vangu, M.; Nyakale, N.E.; Steyn, R.; Gutta, A.A.; Hart, G.; Mutambirwa, S.; et al. South African guidelines for receptor radioligand therapy (RLT) with Lu-177-PSMA in prostate cancer. S. Afr. J. Surg. 2019, 57, 45-51. [CrossRef] [PubMed]

11. Uçmak, G.; Ak Sivrikoz, İ; Alan Selçuk, N.; Demirci, E.; Elboğa, U.; Türkmen, C.; Kabasakal, L. Procedur Guideline for Prostate Cancer Imaging: Ga68 PSMA PET/CT. Nucl. Med. Semin. 2020, 6, 370-384. [CrossRef]

12. Ak Sivrikoz, İ.; Uçmak, G.; Kaya Çapa, G.; Demirci, E.; Alan Selçuk, N.; Türkmen, C.; Elboğa, U.; Kabasakal, L. Procedure Guidelines for Lu-177 PSMA Radyoligand Treatment. Nucl. Med. Semin. 2020, 6, 385-396. [CrossRef]

13. Fanti, S.; Goffin, K.; Hadaschik, B.A.; Herrmann, K.; Maurer, T.; MacLennan, S.; Oprea-Lager, D.E.; Oyen, W.J.; Rouviere, O.; Mottet, N.; et al. Consensus statements on PSMA PET/CT response assessment criteria in prostate cancer. Eur. J. Nucl. Med. Mol. Imaging 2021, 48, 469-476. [CrossRef] [PubMed]

14. Mottet, N.; van den Bergh, R.C.N.; Briers, E.; Van den Broeck, T.; Cumberbatch, M.G.; De Santis, M.; Fanti, S.; Fossati, N.; Gandaglia, G.; Gillessen, S.; et al. EAU-EANM-ESTRO-ESUR-SIOG Guidelines on Prostate Cancer-2020 Update. Part 1: Screening, Diagnosis, and Local Treatment with Curative Intent. Eur. Urol. 2021, 79, 243-262. [CrossRef] [PubMed]

15. Cornford, P.; van den Bergh, R.C.N.; Briers, E.; Van den Broeck, T.; Cumberbatch, M.G.; De Santis, M.; Fanti, S.; Fossati, N.; Gandaglia, G.; Gillessen, S.; et al. EAU-EANM-ESTRO-ESUR-SIOG Guidelines on Prostate Cancer. Part II-2020 Update: Treatment of Relapsing and Metastatic Prostate Cancer. Eur. Urol. 2021, 79, 263-282. [CrossRef] [PubMed]

16. Ceci, F.; Oprea-Lager, D.E.; Emmett, L.; Adam, J.A.; Bomanji, J.; Czernin, J.; Eiber, M.; Haberkorn, U.; Hofman, M.S.; Hope, T.A.; et al. E-PSMA: The EANM standardized reporting guidelines v1.0 for PSMA-PET. Eur. J. Nucl. Med. Mol. Imaging 2021, 48, 1626-1638. [CrossRef] [PubMed] 
17. Shaygan, B.; Zukotynski, K.; Benard, F.; Menard, C.; Kuk, J.; Sistani, G.; Bauman, G.; Veit-Haibach, P.; Metser, U. Canadian Urological Association best practice report: Prostate-specific membrane antigen positron emission tomography/computed tomography (PSMA PET/CT) and PET/magnetic resonance (MR) in prostate cancer. Can. Urol Assoc. J. 2021, 15, 162-172. [CrossRef] [PubMed]

18. Beyersdorff, D.; Rahbar, K.; Essler, M.; Ganswindt, U.; Grosu, A.L.; Gschwend, J.E.; Miller, K.; Scheidhauer, K.; Schlemmer, H.P.; Wolff, J.M.; et al. Interdisciplinary expert consensus on innovations in imaging diagnostics and radionuclide-based therapies for advanced prostate cancer. Urol. A 2021, 60, 1579-1585. [CrossRef]

19. Jadvar, H.; Calais, J.; Fanti, S.; Feng, F.; Greene, K.L.; Gulley, J.L.; Hofman, M.; Koontz, B.F.; Lin, D.W.; Morris, M.J.; et al. Appropriate Use Criteria for Prostate-Specific Membrane Antigen PET Imaging. J. Nucl. Med. 2021. [CrossRef]

20. Eder, M.; Schafer, M.; Bauder-Wust, U.; Hull, W.E.; Wangler, C.; Mier, W.; Haberkorn, U.; Eisenhut, M. 68Ga-complex lipophilicity and the targeting property of a urea-based PSMA inhibitor for PET imaging. Bioconjug Chem. 2012, 23, 688-697. [CrossRef]

21. Afshar-Oromieh, A.; da Cunha, M.L.; Wagner, J.; Haberkorn, U.; Debus, N.; Weber, W.; Eiber, M.; Holland-Letz, T.; Rauscher, I. Performance of [(68)Ga]Ga-PSMA-11 PET/CT in patients with recurrent prostate cancer after prostatectomy-a multi-centre evaluation of 2533 patients. Eur. J. Nucl. Med. Mol. Imaging 2021, 48, 2925-2934. [CrossRef] [PubMed]

22. Abghari-Gerst, M.; Armstrong, W.R.; Nguyen, K.; Calais, J.; Czernin, J.; Lin, D.; Jariwala, N.; Rodnick, M.; Hope, T.A.; Hearn, J.; et al. A comprehensive assessment of (68)Ga-PSMA-11 PET in biochemically recurrent prostate cancer: Results from a prospective multi-center study in 2005 patients. J. Nucl. Med. 2021. [CrossRef] [PubMed]

23. Ferdinandus, J.; Fendler, W.P.; Farolfi, A.; Washington, S.; Mohamad, O.; Pampaloni, M.H.; Scott, P.J.; Rodnick, M.; Viglianti, B.L.; Eiber, M.; et al. PSMA PET validates higher rates of metastatic disease for European Association of Urology Biochemical Recurrence Risk Groups: An international multicenter study. J. Nucl. Med. 2021. [CrossRef]

24. Chen, Y.; Pullambhatla, M.; Foss, C.A.; Byun, Y.; Nimmagadda, S.; Senthamizhchelvan, S.; Sgouros, G.; Mease, R.C.; Pomper, M.G. 2-(3-\{1-Carboxy-5-[(6-[18F]fluoro-pyridine-3-carbonyl)-amino]-pentyl\}-ureido)-pen tanedioic acid, [18F]DCFPyL, a PSMA-based PET imaging agent for prostate cancer. Clin. Cancer Res. 2011, 17, 7645-7653. [CrossRef] [PubMed]

25. Morris, M.J.; Rowe, S.P.; Gorin, M.A.; Saperstein, L.; Pouliot, F.; Josephson, D.; Wong, J.Y.C.; Pantel, A.R.; Cho, S.Y.; Gage, K.L.; et al. Diagnostic Performance of (18)F-DCFPyL-PET/CT in Men with Biochemically Recurrent Prostate Cancer: Results from the CONDOR Phase III, Multicenter Study. Clin. Cancer Res. 2021, 27, 3674-3682. [CrossRef]

26. Pienta, K.J.; Gorin, M.A.; Rowe, S.P.; Carroll, P.R.; Pouliot, F.; Probst, S.; Saperstein, L.; Preston, M.A.; Alva, A.S.; Patnaik, A.; et al. A Phase 2/3 Prospective Multicenter Study of the Diagnostic Accuracy of Prostate Specific Membrane Antigen PET/CT with (18)F-DCFPyL in Prostate Cancer Patients (OSPREY). J. Urol. 2021, 206, 52-61. [CrossRef]

27. Bodar, Y.J.L.; Zwezerijnen, B.; van der Voorn, P.J.; Jansen, B.H.E.; Smit, R.S.; Kol, S.Q.; Meijer, D.; de Bie, K.; Yaqub, M.; Windhorst, B.A.D.; et al. Prospective analysis of clinically significant prostate cancer detection with [(18)F]DCFPyL PET/MRI compared to multiparametric MRI: A comparison with the histopathology in the radical prostatectomy specimen, the ProStaPET study. Eur. J. Nucl. Med. Mol. Imaging 2021. [CrossRef] [PubMed]

28. FDA Approves First PSMA-Targeted PET Imaging Drug for Men with Prostate Cancer. 2020. Available online: https://www.fda. gov/news-events / press-announcements/fda-approves-first-psma-targeted-pet-imaging-drug-men-prostate-cancer (accessed on 26 October 2021).

29. Carlucci, G.; Ippisch, R.; Slavik, R.; Mishoe, A.; Blecha, J.; Zhu, S. (68)Ga-PSMA-11 NDA Approval: A Novel and Successful Academic Partnership. J. Nucl Med. 2021, 62, 149-155. [CrossRef] [PubMed]

30. Sartor, O.; Hope, T.A.; Calais, J.; Fendler, W.P. Oliver Sartor Talks with Thomas, A. Hope, Jeremie Calais, and Wolfgang, P. Fendler About FDA Approval of PSMA. J. Nucl. Med. 2021, 62, 146-148. [CrossRef] [PubMed]

31. Masters, S.C.; Hofling, A.A.; Gorovets, A.; Marzella, L. FDA Approves Ga 68 PSMA-11 for Prostate Cancer Imaging. Int. J. Radiat. Oncol. Biol. Phys. 2021, 111, 27-28. [CrossRef]

32. Hennrich, U.; Eder, M. [(68)Ga]Ga-PSMA-11: The First FDA-Approved (68)Ga-Radiopharmaceutical for PET Imaging of Prostate Cancer. Pharmaceuticals 2021, 14, 713. [CrossRef]

33. FDA Approves Second PSMA-Targeted PET Imaging Drug for Men with Prostate Cancer. 2021. Available online: https://www. fda.gov / drugs / drug-safety-and-availability / fda-approves-second-psma-targeted-pet-imaging-drug-men-prostate-cancer (accessed on 26 October 2021).

34. Song, H.; Iagaru, A.; Rowe, S.P. (18)F DCFPyL PET Acquisition, Interpretation and Reporting: Suggestions Post Food and Drug Administration Approval. J. Nucl. Med. 2021. [CrossRef] [PubMed]

35. Cardinale, J.; Schafer, M.; Benesova, M.; Bauder-Wust, U.; Leotta, K.; Eder, M.; Neels, O.C.; Haberkorn, U.; Giesel, F.L.; Kopka, K. Preclinical Evaluation of (18)F-PSMA-1007, a New Prostate-Specific Membrane Antigen Ligand for Prostate Cancer Imaging. J. Nucl. Med. 2017, 58, 425-431. [CrossRef]

36. Giesel, F.L.; Knorr, K.; Spohn, F.; Will, L.; Maurer, T.; Flechsig, P.; Neels, O.; Schiller, K.; Amaral, H.; Weber, W.A.; et al. Detection Efficacy of (18)F-PSMA-1007 PET/CT in 251 Patients with Biochemical Recurrence of Prostate Cancer After Radical Prostatectomy. J. Nucl. Med. 2019, 60, 362-368. [CrossRef] [PubMed]

37. Sprute, K.; Kramer, V.; Koerber, S.A.; Meneses, M.; Fernandez, R.; Soza-Ried, C.; Eiber, M.; Weber, W.A.; Rauscher, I.; Rahbar, K.; et al. Diagnostic Accuracy of (18)F-PSMA-1007 PET/CT Imaging for Lymph Node Staging of Prostate Carcinoma in Primary and Biochemical Recurrence. J. Nucl. Med. 2021, 62, 208-213. [CrossRef] [PubMed] 
38. Malaspina, S.; Anttinen, M.; Taimen, P.; Jambor, I.; Sandell, M.; Rinta-Kiikka, I.; Kajander, S.; Schildt, J.; Saukko, E.; Noponen, T.; et al. Prospective comparison of (18)F-PSMA-1007 PET/CT, whole-body MRI and CT in primary nodal staging of unfavourable intermediate- and high-risk prostate cancer. Eur J. Nucl. Med. Mol. Imaging 2021, 48, 2951-2959. [CrossRef] [PubMed]

39. Vallabhajosula, S.; Nikolopoulou, A.; Babich, J.W.; Osborne, J.R.; Tagawa, S.T.; Lipai, I.; Solnes, L.; Maresca, K.P.; Armor, T.; Joyal, J.L.; et al. 99mTc-labeled small-molecule inhibitors of prostate-specific membrane antigen: Pharmacokinetics and biodistribution studies in healthy subjects and patients with metastatic prostate cancer. J. Nucl. Med. 2014, 55, 1791-1798. [CrossRef]

40. Goffin, K.E.; Joniau, S.; Tenke, P.; Slawin, K.; Klein, E.A.; Stambler, N.; Strack, T.; Babich, J.; Armor, T.; Wong, V. Phase 2 Study of (99m)Tc-Trofolastat SPECT/CT to Identify and Localize Prostate Cancer in Intermediate- and High-Risk Patients Undergoing Radical Prostatectomy and Extended Pelvic LN Dissection. J. Nucl. Med. 2017, 58, 1408-1413. [CrossRef]

41. Schmidkonz, C.; Hollweg, C.; Beck, M.; Reinfelder, J.; Goetz, T.I.; Sanders, J.C.; Schmidt, D.; Prante, O.; Bauerle, T.; Cavallaro, A.; et al. (99m) Tc-MIP-1404-SPECT/CT for the detection of PSMA-positive lesions in 225 patients with biochemical recurrence of prostate cancer. Prostate 2018, 78, 54-63. [CrossRef]

42. Schmidkonz, C.; Cordes, M.; Beck, M.; Goetz, T.I.; Schmidt, D.; Prante, O.; Bauerle, T.; Uder, M.; Wullich, B.; Goebell, P.; et al. SPECT/CT With the PSMA Ligand 99mTc-MIP-1404 for Whole-Body Primary Staging of Patients With Prostate Cancer. Clin. Nucl. Med. 2018, 43, 225-231. [CrossRef]

43. EDQM. European Pharmacopoeia, 10th ed.; Council of Europe: Strasbourg, France, 2021.

44. Alberts, I.L.; Seide, S.E.; Mingels, C.; Bohn, K.P.; Shi, K.; Zacho, H.D.; Rominger, A.; Afshar-Oromieh, A. Comparing the diagnostic performance of radiotracers in recurrent prostate cancer: A systematic review and network meta-analysis. Eur J. Nucl. Med. Mol. Imaging 2021, 48, 2978-2989. [CrossRef]

45. Weineisen, M.; Schottelius, M.; Simecek, J.; Baum, R.P.; Yildiz, A.; Beykan, S.; Kulkarni, H.R.; Lassmann, M.; Klette, I.; Eiber, M.; et al. 68Ga- and 177Lu-Labeled PSMA I\&T: Optimization of a PSMA-Targeted Theranostic Concept and First Proof-of-Concept Human Studies. J. Nucl. Med. 2015, 56, 1169-1176. [CrossRef]

46. Heck, M.M.; Tauber, R.; Schwaiger, S.; Retz, M.; D’Alessandria, C.; Maurer, T.; Gafita, A.; Wester, H.J.; Gschwend, J.E.; Weber, W.A.; et al. Treatment Outcome, Toxicity, and Predictive Factors for Radioligand Therapy with (177)Lu-PSMA-I\&T in Metastatic Castration-resistant Prostate Cancer. Eur. Urol. 2019, 75, 920-926. [CrossRef] [PubMed]

47. Prive, B.M.; Janssen, M.J.R.; van Oort, I.M.; Muselaers, C.H.J.; Jonker, M.A.; de Groot, M.; Mehra, N.; Verzijlbergen, J.F.; Scheenen, T.W.J.; Zamecnik, P.; et al. Lutetium-177-PSMA-I\&T as metastases directed therapy in oligometastatic hormone sensitive prostate cancer, a randomized controlled trial. BMC Cancer 2020, 20, 884. [CrossRef]

48. Zacherl, M.J.; Gildehaus, F.J.; Mittlmeier, L.; Boning, G.; Gosewisch, A.; Wenter, V.; Unterrainer, M.; Schmidt-Hegemann, N.; Belka, C.; Kretschmer, A.; et al. First Clinical Results for PSMA-Targeted alpha-Therapy Using (225)Ac-PSMA-I\&T in AdvancedmCRPC Patients. J. Nucl. Med. 2021, 62, 669-674. [CrossRef]

49. Benesova, M.; Schafer, M.; Bauder-Wust, U.; Afshar-Oromieh, A.; Kratochwil, C.; Mier, W.; Haberkorn, U.; Kopka, K.; Eder, M. Preclinical Evaluation of a Tailor-Made DOTA-Conjugated PSMA Inhibitor with Optimized Linker Moiety for Imaging and Endoradiotherapy of Prostate Cancer. J. Nucl. Med. 2015, 56, 914-920. [CrossRef]

50. Rahbar, K.; Ahmadzadehfar, H.; Kratochwil, C.; Haberkorn, U.; Schafers, M.; Essler, M.; Baum, R.P.; Kulkarni, H.R.; Schmidt, M.; Drzezga, A.; et al. German Multicenter Study Investigating 177Lu-PSMA-617 Radioligand Therapy in Advanced Prostate Cancer Patients. J. Nucl. Med. 2017, 58, 85-90. [CrossRef] [PubMed]

51. Kratochwil, C.; Bruchertseifer, F.; Rathke, H.; Hohenfellner, M.; Giesel, F.L.; Haberkorn, U.; Morgenstern, A. Targeted alphaTherapy of Metastatic Castration-Resistant Prostate Cancer with (225)Ac-PSMA-617: Swimmer-Plot Analysis Suggests Efficacy Regarding Duration of Tumor Control. J. Nucl. Med. 2018, 59, 795-802. [CrossRef]

52. Khreish, F.; Ghazal, Z.; Marlowe, R.J.; Rosar, F.; Sabet, A.; Maus, S.; Linxweiler, J.; Bartholoma, M.; Ezziddin, S. 177 Lu-PSMA-617 radioligand therapy of metastatic castration-resistant prostate cancer: Initial 254-patient results from a prospective registry (REALITY Study). Eur J. Nucl. Med. Mol. Imaging 2021. [CrossRef]

53. Morris, M.J.; De Bono, J.S.; Chi, K.N.; Fizazi, K.; Herrmann, K.; Rahbar, K.; Tagawa, S.T.; Nordquist, L.T.; Vaishampayan, N.; El-Haddad, G.; et al. Phase III study of lutetium-177-PSMA-617 in patients with metastatic castration-resistant prostate cancer (VISION). J. Clin. Oncol. 2021, 39, LBA4. [CrossRef]

54. Dolgin, E. Drugmakers go nuclear, continuing push into radiopharmaceuticals. Nat. Biotechnol 2021, 39, 647-649. [CrossRef] [PubMed]

55. Sartor, O.; de Bono, J.; Chi, K.N.; Fizazi, K.; Herrmann, K.; Rahbar, K.; Tagawa, S.T.; Nordquist, L.T.; Vaishampayan, N.; El-Haddad, G.; et al. Lutetium-177-PSMA-617 for Metastatic Castration-Resistant Prostate Cancer. N. Engl. J. Med. 2021, 385, 1091-1103. [CrossRef] [PubMed]

56. Zippel, C.; Giesel, F.L.; Kratochwil, C.; Eiber, M.; Rahbar, K.; Albers, P.; Maurer, T.; Krause, B.J.; Bohnet-Joschko, S. PSMA radioligand therapy could pose infrastructural challenges for nuclear medicine: Results of a basic calculation for the capacity planning of nuclear medicine beds in the German hospital sector. Nuklearmedizin 2021, 60, 216-223. [CrossRef] [PubMed]

57. Viljoen, B.; Hofman, M.S.; Chambers, S.K.; Dunn, J.; Dhillon, H.; Davis, I.D.; Ralph, N. Advanced prostate cancer experimental radioactive treatment-clinical trial decision making: Patient experiences. BMJ Support. Palliat Care 2021. [CrossRef] [PubMed]

58. Srinivas, S.; Iagaru, A. To Scan or Not to Scan: An Unnecessary Dilemma for PSMA Radioligand Therapy. J. Nucl. Med. 2021, 62, 1487-1488. [CrossRef] [PubMed] 
59. Calais, J.; Czernin, J. PSMA Expression Assessed by PET Imaging Is a Required Biomarker for Selecting Patients for Any PSMA-Targeted Therapy. J. Nucl. Med. 2021, 62, 1489-1491. [CrossRef] [PubMed]

60. Herrmann, K.; Kraus, B.J.; Hadaschik, B.; Kunikowska, J.; van Poppel, H.; N’Dow, J.; Sartor, O.; Oyen, W.J.G. Nuclear medicine theranostics comes of age. Lancet Oncol. 2021, 22, 1497-1498. [CrossRef]

61. Czernin, J. Reply: PSMA-Targeted Therapeutics: A Tale About Law and Economics. J. Nucl. Med. 2021, 62, 1483. [CrossRef]

62. Zippel, C.; Ronski, S.C.; Bohnet-Joschko, S.; Giesel, F.L.; Kopka, K. Current Status of PSMA-Radiotracers for Prostate Cancer: Data Analysis of Prospective Trials Listed on ClinicalTrials.gov. Pharmaceuticals 2020, 13, 12. [CrossRef] [PubMed]

63. Sandhu, S.; Guo, C.; Hofman, M.S. Radionuclide Therapy in Prostate Cancer: From standalone to combination PSMA theranostics. J. Nucl. Med. 2021. [CrossRef] [PubMed]

64. Zhang, H.; Koumna, S.; Pouliot, F.; Beauregard, J.M.; Kolinsky, M. PSMA Theranostics: Current Landscape and Future Outlook. Cancers 2021, 13, 23. [CrossRef]

65. Kopka, K.; Benesova, M.; Barinka, C.; Haberkorn, U.; Babich, J. Glu-Ureido-Based Inhibitors of Prostate-Specific Membrane Antigen: Lessons Learned During the Development of a Novel Class of Low-Molecular-Weight Theranostic Radiotracers. J. Nucl. Med. 2017, 58, 17S-26S. [CrossRef]

66. Szabo, Z.; Mena, E.; Rowe, S.P.; Plyku, D.; Nidal, R.; Eisenberger, M.A.; Antonarakis, E.S.; Fan, H.; Dannals, R.F.; Chen, Y.; et al. Initial Evaluation of [(18)F]DCFPyL for Prostate-Specific Membrane Antigen (PSMA)-Targeted PET Imaging of Prostate Cancer. Mol. Imaging Biol. 2015, 17, 565-574. [CrossRef]

67. Afshar-Oromieh, A.; Haberkorn, U.; Eder, M.; Eisenhut, M.; Zechmann, C.M. [68Ga]Gallium-labelled PSMA ligand as superior PET tracer for the diagnosis of prostate cancer: Comparison with 18F-FECH. Eur J. Nucl. Med. Mol. Imaging 2012, 39, 1085-1086. [CrossRef] [PubMed]

68. Malik, N.; Baur, B.; Winter, G.; Reske, S.N.; Beer, A.J.; Solbach, C. Radiofluorination of PSMA-HBED via Al(18)F(2+) Chelation and Biological Evaluations In Vitro. Mol. Imaging Biol. 2015, 17, 777-785. [CrossRef] [PubMed]

69. Piron, S.; De Man, K.; Van Laeken, N.; D'Asseler, Y.; Bacher, K.; Kersemans, K.; Ost, P.; Decaestecker, K.; Deseyne, P.; Fonteyne, V.; et al. Radiation Dosimetry and Biodistribution of (18)F-PSMA-11 for PET Imaging of Prostate Cancer. J. Nucl. Med. 2019, 60, 1736-1742. [CrossRef]

70. Giesel, F.L.; Cardinale, J.; Schafer, M.; Neels, O.; Benesova, M.; Mier, W.; Haberkorn, U.; Kopka, K.; Kratochwil, C. (18)F-Labelled PSMA-1007 shows similarity in structure, biodistribution and tumour uptake to the theragnostic compound PSMA-617. Eur J. Nucl. Med. Mol. Imaging 2016, 43, 1929-1930. [CrossRef] [PubMed]

71. Umbricht, C.A.; Benesova, M.; Schmid, R.M.; Turler, A.; Schibli, R.; van der Meulen, N.P.; Muller, C. (44)Sc-PSMA-617 for radiotheragnostics in tandem with (177)Lu-PSMA-617-preclinical investigations in comparison with (68)Ga-PSMA-11 and (68)Ga-PSMA-617. EJNMMI Res. 2017, 7, 9. [CrossRef]

72. Eppard, E.; de la Fuente, A.; Benesova, M.; Khawar, A.; Bundschuh, R.A.; Gartner, F.C.; Kreppel, B.; Kopka, K.; Essler, M.; Rosch, F. Clinical Translation and First In-Human Use of [(44)Sc]Sc-PSMA-617 for PET Imaging of Metastasized Castrate-Resistant Prostate Cancer. Theranostics 2017, 7, 4359-4369. [CrossRef]

73. Grubmuller, B.; Baum, R.P.; Capasso, E.; Singh, A.; Ahmadi, Y.; Knoll, P.; Floth, A.; Righi, S.; Zandieh, S.; Meleddu, C.; et al. (64)Cu-PSMA-617 PET/CT Imaging of Prostate Adenocarcinoma: First In-Human Studies. Cancer Biother. Radiopharm. 2016, 31, 277-286. [CrossRef]

74. Afshar-Oromieh, A.; Hetzheim, H.; Kratochwil, C.; Benesova, M.; Eder, M.; Neels, O.C.; Eisenhut, M.; Kubler, W.; Holland-Letz, T.; Giesel, F.L.; et al. The Theranostic PSMA Ligand PSMA-617 in the Diagnosis of Prostate Cancer by PET/CT: Biodistribution in Humans, Radiation Dosimetry, and First Evaluation of Tumor Lesions. J. Nucl. Med. 2015, 56, 1697-1705. [CrossRef]

75. Mix, M.; Reichel, K.; Stoykow, C.; Bartholoma, M.; Drendel, V.; Gourni, E.; Wetterauer, U.; Schultze-Seemann, W.; Meyer, P.T.; Jilg, C.A. Performance of (111)In-labelled PSMA ligand in patients with nodal metastatic prostate cancer: Correlation between tracer uptake and histopathology from lymphadenectomy. Eur. J. Nucl. Med. Mol. Imaging 2018, 45, 2062-2070. [CrossRef] [PubMed]

76. Muller, C.; Singh, A.; Umbricht, C.A.; Kulkarni, H.R.; Johnston, K.; Benesova, M.; Senftleben, S.; Muller, D.; Vermeulen, C.; Schibli, R.; et al. Preclinical investigations and first-in-human application of (152)Tb-PSMA-617 for PET/CT imaging of prostate cancer. EJNMMI Res. 2019, 9, 68. [CrossRef]

77. Kratochwil, C.; Giesel, F.L.; Eder, M.; Afshar-Oromieh, A.; Benesova, M.; Mier, W.; Kopka, K.; Haberkorn, U. [(1)(7)(7)Lu]Lutetiumlabelled PSMA ligand-induced remission in a patient with metastatic prostate cancer. Eur. J. Nucl. Med. Mol. Imaging 2015, 42, 987-988. [CrossRef] [PubMed]

78. Kratochwil, C.; Bruchertseifer, F.; Giesel, F.L.; Weis, M.; Verburg, F.A.; Mottaghy, F.; Kopka, K.; Apostolidis, C.; Haberkorn, U.; Morgenstern, A. 225Ac-PSMA-617 for PSMA-Targeted alpha-Radiation Therapy of Metastatic Castration-Resistant Prostate Cancer. J. Nucl. Med. 2016, 57, 1941-1944. [CrossRef]

79. Schottelius, M.; Wirtz, M.; Eiber, M.; Maurer, T.; Wester, H.J. [(111)In]PSMA-I\&T: Expanding the spectrum of PSMA-I\&T applications towards SPECT and radioguided surgery. EJNMMI Res. 2015, 5, 68. [CrossRef] [PubMed]

80. Maurer, T.; Weirich, G.; Schottelius, M.; Weineisen, M.; Frisch, B.; Okur, A.; Kubler, H.; Thalgott, M.; Navab, N.; Schwaiger, M.; et al. Prostate-specific membrane antigen-radioguided surgery for metastatic lymph nodes in prostate cancer. Eur. Urol. 2015, 68, 530-534. [CrossRef] 
81. Robu, S.; Schottelius, M.; Eiber, M.; Maurer, T.; Gschwend, J.; Schwaiger, M.; Wester, H.J. Preclinical Evaluation and First Patient Application of 99mTc-PSMA-I\&S for SPECT Imaging and Radioguided Surgery in Prostate Cancer. J. Nucl. Med. 2017, 58, 235-242. [CrossRef]

82. Reinfelder, J.; Kuwert, T.; Beck, M.; Sanders, J.C.; Ritt, P.; Schmidkonz, C.; Hennig, P.; Prante, O.; Uder, M.; Wullich, B.; et al. First Experience With SPECT/CT Using a 99mTc-Labeled Inhibitor for Prostate-Specific Membrane Antigen in Patients With Biochemical Recurrence of Prostate Cancer. Clin. Nucl. Med. 2017, 42, 26-33. [CrossRef] [PubMed]

83. Wurzer, A.; Parzinger, M.; Konrad, M.; Beck, R.; Gunther, T.; Felber, V.; Farber, S.; Di Carlo, D.; Wester, H.J. Preclinical comparison of four [(18)F, (nat)Ga]rhPSMA-7 isomers: Influence of the stereoconfiguration on pharmacokinetics. EJNMMI Res. 2020, 10, 149. [CrossRef]

84. Tolvanen, T.; Kalliokoski, K.; Malaspina, S.; Kuisma, A.; Lahdenpohja, S.; Postema, E.J.; Miller, M.P.; Scheinin, M. Safety, Biodistribution, and Radiation Dosimetry of (18)F-rhPSMA-7.3 in Healthy Adult Volunteers. J. Nucl. Med. 2021, 62, 679-684. [CrossRef]

85. Yusufi, N.; Wurzer, A.; Herz, M.; D’Alessandria, C.; Feuerecker, B.; Weber, W.; Wester, H.J.; Nekolla, S.; Eiber, M. Comparative Preclinical Biodistribution, Dosimetry, and Endoradiotherapy in Metastatic Castration-Resistant Prostate Cancer Using (19)F/(177)Lu-rhPSMA-7.3 and (177)Lu-PSMA I\&T. J. Nucl. Med. 2021, 62, 1106-1111. [CrossRef]

86. Feuerecker, B.; Chantadisai, M.; Allmann, A.; Tauber, R.; Allmann, J.; Steinhelfer, L.; Rauscher, I.; Wurzer, A.; Wester, H.J.; Weber, W.A.; et al. Pre-therapeutic comparative dosimetry of (177)Lu-rhPSMA-7.3 and (177)Lu-PSMAI\&T in patients with metastatic castration resistant prostate cancer (mCRPC). J. Nucl. Med. 2021. [CrossRef]

87. Zlatopolskiy, B.D.; Endepols, H.; Krapf, P.; Guliyev, M.; Urusova, E.A.; Richarz, R.; Hohberg, M.; Dietlein, M.; Drzezga, A.; Neumaier, B. Discovery of (18)F-JK-PSMA-7, a PET Probe for the Detection of Small PSMA-Positive Lesions. J. Nucl. Med. 2019, 60, 817-823. [CrossRef] [PubMed]

88. Hohberg, M.; Kobe, C.; Krapf, P.; Tager, P.; Hammes, J.; Dietlein, F.; Zlatopolskiy, B.D.; Endepols, H.; Wild, M.; Neubauer, S.; et al. Biodistribution and radiation dosimetry of [(18)F]-JK-PSMA-7 as a novel prostate-specific membrane antigen-specific ligand for PET/CT imaging of prostate cancer. EJNMMI Res. 2019, 9, 66. [CrossRef]

89. Young, J.D.; Abbate, V.; Imberti, C.; Meszaros, L.K.; Ma, M.T.; Terry, S.Y.A.; Hider, R.C.; Mullen, G.E.; Blower, P.J. (68)Ga-THPPSMA: A PET Imaging Agent for Prostate Cancer Offering Rapid, Room-Temperature, 1-Step Kit-Based Radiolabeling. J. Nucl. Med. 2017, 58, 1270-1277. [CrossRef]

90. Hofman, M.S.; Eu, P.; Jackson, P.; Hong, E.; Binns, D.; Iravani, A.; Murphy, D.; Mitchell, C.; Siva, S.; Hicks, R.J.; et al. Cold Kit for Prostate-Specific Membrane Antigen (PSMA) PET Imaging: Phase 1 Study of (68)Ga-Tris(Hydroxypyridinone)-PSMA PET/CT in Patients with Prostate Cancer. Nucl. Med. 2018, 59, 625-631. [CrossRef]

91. Iudicello, A.; Genovese, F.; Di Iorio, V.; Cicoria, G.; Boschi, S. An HPLC and UHPLC-HRMS approach to study PSMA-11 instability in aqueous solution. EJNMMI Radiopharm. Chem. 2021, 6, 14. [CrossRef] [PubMed]

92. Eder, M.; Neels, O.; Muller, M.; Bauder-Wust, U.; Remde, Y.; Schafer, M.; Hennrich, U.; Eisenhut, M.; Afshar-Oromieh, A.; Haberkorn, U.; et al. Novel Preclinical and Radiopharmaceutical Aspects of [68Ga]Ga-PSMA-HBED-CC: A New PET Tracer for Imaging of Prostate Cancer. Pharmaceuticals 2014, 7, 779-796. [CrossRef] [PubMed]

93. Martin, S.; Tonnesmann, R.; Hierlmeier, I.; Maus, S.; Rosar, F.; Ruf, J.; Holland, J.P.; Ezziddin, S.; Bartholoma, M.D. Identification, Characterization, and Suppression of Side Products Formed during the Synthesis of [(177)Lu]Lu-PSMA-617. J. Med. Chem 2021, 64, 4960-4971. [CrossRef]

94. Thiele, N.A.; Brown, V.; Kelly, J.M.; Amor-Coarasa, A.; Jermilova, U.; MacMillan, S.N.; Nikolopoulou, A.; Ponnala, S.; Ramogida, C.F.; Robertson, A.K.H.; et al. An Eighteen-Membered Macrocyclic Ligand for Actinium-225 Targeted Alpha Therapy. Angew. Chem. Int. Ed. Engl. 2017, 56, 14712-14717. [CrossRef]

95. Reissig, F.; Bauer, D.; Zarschler, K.; Novy, Z.; Bendova, K.; Ludik, M.C.; Kopka, K.; Pietzsch, H.J.; Petrik, M.; Mamat, C. Towards Targeted Alpha Therapy with Actinium-225: Chelators for Mild Condition Radiolabeling and Targeting PSMA-A Proof of Concept Study. Cancers 2021, 13, 974. [CrossRef]

96. Mukherjee, A. An Update on Extemporaneous Preparation of Radiopharmaceuticals Using Freeze-Dried Cold Kits. Mini Rev. Med. Chem. 2021, 21, 1322-1336. [CrossRef]

97. Satpati, D. Recent Breakthrough in (68)Ga-Radiopharmaceuticals Cold Kits for Convenient PET Radiopharmacy. Bioconjug Chem. 2021, 32, 430-447. [CrossRef] [PubMed]

98. Australian TGA Approves Illuccix®for Prostate Cancer Imaging. Available online: https://telixpharma.com/wp-content/ uploads/TLX_Australian_TGA_Approves_Illuccix_for_Prostate_Cancer_Imaging.pdf (accessed on 2 November 2021).

99. Baum, R.P.; Langbein, T.; Singh, A.; Shahinfar, M.; Schuchardt, C.; Volk, G.F.; Kulkarni, H. Injection of Botulinum Toxin for Preventing Salivary Gland Toxicity after PSMA Radioligand Therapy: An Empirical Proof of a Promising Concept. Nucl. Med. Mol. Imaging 2018, 52, 80-81. [CrossRef]

100. Taieb, D.; Foletti, J.M.; Bardies, M.; Rocchi, P.; Hicks, R.J.; Haberkorn, U. PSMA-Targeted Radionuclide Therapy and Salivary Gland Toxicity: Why Does It Matter? J. Nucl. Med. 2018, 59, 747-748. [CrossRef] [PubMed]

101. Langbein, T.; Chausse, G.; Baum, R.P. Salivary Gland Toxicity of PSMA Radioligand Therapy: Relevance and Preventive Strategies. J. Nucl. Med. 2018, 59, 1172-1173. [CrossRef] [PubMed]

102. Mohan, V.; Bruin, N.M.; van de Kamer, J.B.; Sonke, J.J.; Vogel, W.V. The effect of eating on the uptake of PSMA ligands in the salivary glands. EJNMMI Res. 2021, 11, 95. [CrossRef] 
103. Heynickx, N.; Herrmann, K.; Vermeulen, K.; Baatout, S.; Aerts, A. The salivary glands as a dose limiting organ of PSMA- targeted radionuclide therapy: A review of the lessons learnt so far. Nucl. Med. Biol 2021, 98-99, 30-39. [CrossRef] [PubMed]

104. Tonnesmann, R.; Meyer, P.T.; Eder, M.; Baranski, A.C. [(177)Lu]Lu-PSMA-617 Salivary Gland Uptake Characterized by Quantitative In Vitro Autoradiography. Pharmaceuticals 2019, 12, 18. [CrossRef] [PubMed]

105. Felber, V.B.; Valentin, M.A.; Wester, H.J. Design of PSMA ligands with modifications at the inhibitor part: An approach to reduce the salivary gland uptake of radiolabeled PSMA inhibitors? EJNMMI Radiopharm. Chem. 2021, 6, 10. [CrossRef]

106. Kalidindi, T.M.; Lee, S.G.; Jou, K.; Chakraborty, G.; Skafida, M.; Tagawa, S.T.; Bander, N.H.; Schoder, H.; Bodei, L.; Pandit-Taskar, N.; et al. A simple strategy to reduce the salivary gland and kidney uptake of PSMA-targeting small molecule radiopharmaceuticals. Eur. J. Nucl. Med. Mol. Imaging 2021, 48, 2642-2651. [CrossRef] [PubMed]

107. Roy, J.; Warner, B.M.; Basuli, F.; Zhang, X.; Zheng, C.; Goldsmith, C.; Phelps, T.; Wong, K.; Ton, A.T.; Pieschl, R.; et al. Competitive blocking of salivary gland [(18)F]DCFPyL uptake via localized, retrograde ductal injection of non-radioactive DCFPyL: A preclinical study. EJNMMI Res. 2021, 11, 66. [CrossRef] [PubMed]

108. Van Leeuwen, F.W.B.; Winter, A.; van Der Poel, H.G.; Eiber, M.; Suardi, N.; Graefen, M.; Wawroschek, F.; Maurer, T. Technologies for image-guided surgery for managing lymphatic metastases in prostate cancer. Nat. Rev. Urol. 2019, 16, 159-171. [CrossRef] [PubMed]

109. Rauscher, I.; Duwel, C.; Wirtz, M.; Schottelius, M.; Wester, H.J.; Schwamborn, K.; Haller, B.; Schwaiger, M.; Gschwend, J.E.; Eiber, M.; et al. Value of (111) In-prostate-specific membrane antigen (PSMA)-radioguided surgery for salvage lymphadenectomy in recurrent prostate cancer: Correlation with histopathology and clinical follow-up. BJU Int. 2017, 120, 40-47. [CrossRef]

110. Jilg, C.A.; Reichel, K.; Stoykow, C.; Rischke, H.C.; Bartholoma, M.; Drendel, V.; von Buren, M.; Schultze-Seemann, W.; Meyer, P.T.; Mix, M. Results from extended lymphadenectomies with [(111)In]PSMA-617 for intraoperative detection of PSMA-PET/CTpositive nodal metastatic prostate cancer. EJNMMI Res. 2020, 10, 17. [CrossRef]

111. Rauscher, I.; Maurer, T.; Souvatzoglou, M.; Beer, A.J.; Vag, T.; Wirtz, M.; Weirich, G.; Wester, H.J.; Gschwend, J.E.; Schwaiger, M.; et al. Intrapatient Comparison of 111In-PSMA I\&T SPECT/CT and Hybrid 68Ga-HBED-CC PSMA PET in Patients With Early Recurrent Prostate Cancer. Clin. Nucl. Med. 2016, 41, e397-e402. [CrossRef]

112. Maurer, T.; Robu, S.; Schottelius, M.; Schwamborn, K.; Rauscher, I.; van den Berg, N.S.; van Leeuwen, F.W.B.; Haller, B.; Horn, T.; Heck, M.M.; et al. (99m)Technetium-based Prostate-specific Membrane Antigen-radioguided Surgery in Recurrent Prostate Cancer. Eur. Urol. 2019, 75, 659-666. [CrossRef]

113. Horn, T.; Kronke, M.; Rauscher, I.; Haller, B.; Robu, S.; Wester, H.J.; Schottelius, M.; van Leeuwen, F.W.B.; van der Poel, H.G.; Heck, M.; et al. Single Lesion on Prostate-specific Membrane Antigen-ligand Positron Emission Tomography and Low Prostatespecific Antigen Are Prognostic Factors for a Favorable Biochemical Response to Prostate-specific Membrane Antigen-targeted Radioguided Surgery in Recurrent Prostate Cancer. Eur. Urol. 2019, 76, 517-523. [CrossRef]

114. Werner, P.; Neumann, C.; Eiber, M.; Wester, H.J.; Schottelius, M. [(99cm)Tc]Tc-PSMA-I\&S-SPECT/CT: Experience in prostate cancer imaging in an outpatient center. EJNMMI Res. 2020, 10, 45. [CrossRef]

115. Urban, S.; Meyer, C.; Dahlbom, M.; Farkas, I.; Sipka, G.; Besenyi, Z.; Czernin, J.; Calais, J.; Pavics, L. Radiation Dosimetry of (99m)Tc-PSMA I\&S: A Single-Center Prospective Study. J. Nucl. Med. 2021, 62, 1075-1081. [CrossRef]

116. Afshar-Oromieh, A.; Hetzheim, H.; Kubler, W.; Kratochwil, C.; Giesel, F.L.; Hope, T.A.; Eder, M.; Eisenhut, M.; Kopka, K.; Haberkorn, U. Radiation dosimetry of (68)Ga-PSMA-11 (HBED-CC) and preliminary evaluation of optimal imaging timing. Eur. J. Nucl. Med. Mol. Imaging 2016, 43, 1611-1620. [CrossRef] [PubMed]

117. Giesel, F.L.; Hadaschik, B.; Cardinale, J.; Radtke, J.; Vinsensia, M.; Lehnert, W.; Kesch, C.; Tolstov, Y.; Singer, S.; Grabe, N.; et al. F-18 labelled PSMA-1007: Biodistribution, radiation dosimetry and histopathological validation of tumor lesions in prostate cancer patients. Eur. J. Nucl. Med. Mol. Imaging 2017, 44, 678-688. [CrossRef]

118. Aalbersberg, E.A.; Verwoerd, D.; Mylvaganan-Young, C.; de Barros, H.A.; van Leeuwen, P.J.; Sonneborn-Bols, M.; Donswijk, M.L. Occupational Radiation Exposure of Radiopharmacy, Nuclear Medicine, and Surgical Personnel During Use of [(99m)Tc]Tc-PSMA-I\&S for Prostate Cancer Surgery. J. Nucl. Med. Technol. 2021, 49, 334-338. [CrossRef]

119. Jeschke, S.; Beri, A.; Grull, M.; Ziegerhofer, J.; Prammer, P.; Leeb, K.; Sega, W.; Janetschek, G. Laparoscopic radioisotope-guided sentinel lymph node dissection in staging of prostate cancer. Eur. Urol. 2008, 53, 126-132. [CrossRef]

120. Meershoek, P.; van Oosterom, M.N.; Simon, H.; Mengus, L.; Maurer, T.; van Leeuwen, P.J.; Wit, E.M.K.; van der Poel, H.G.; van Leeuwen, F.W.B. Robot-assisted laparoscopic surgery using DROP-IN radioguidance: First-in-human translation. Eur. J. Nucl. Med. Mol. Imaging 2019, 46, 49-53. [CrossRef] [PubMed]

121. Van Oosterom, M.N.; Simon, H.; Mengus, L.; Welling, M.; Van der Poel, H.G.; Van den Berg, N.S.; Van Leeuwen, F.W. Revolutionizing (robot-assisted) laparoscopic gamma tracing using a drop-in gamma probe technology. Am. J. Nucl. Med. Mol. Imaging 2016, $6,1-17$.

122. Van Leeuwen, F.W.B.; van Oosterom, M.N.; Meershoek, P.; van Leeuwen, P.J.; Berliner, C.; van der Poel, H.G.; Graefen, M.; Maurer, T. Minimal-Invasive Robot-Assisted Image-Guided Resection of Prostate-Specific Membrane Antigen-Positive Lymph Nodes in Recurrent Prostate Cancer. Clin. Nucl Med. 2019, 44, 580-581. [CrossRef] [PubMed]

123. Collamati, F.; van Oosterom, M.N.; De Simoni, M.; Faccini, R.; Fischetti, M.; Mancini Terracciano, C.; Mirabelli, R.; Moretti, R.; Heuvel, J.O.; Solfaroli Camillocci, E.; et al. A DROP-IN beta probe for robot-assisted (68)Ga-PSMA radioguided surgery: First ex vivo technology evaluation using prostate cancer specimens. EJNMMI Res. 2020, 10, 92. [CrossRef] 
124. Olde Heuvel, J.; de Wit-van der Veen, B.J.; Vyas, K.N.; Tuch, D.S.; Grootendorst, M.R.; Stokkel, M.P.M.; Slump, C.H. Performance evaluation of Cerenkov luminescence imaging: A comparison of (68)Ga with (18)F. EJNMMI Phys. 2019, 6, 17. [CrossRef]

125. Darr, C.; Harke, N.N.; Radtke, J.P.; Yirga, L.; Kesch, C.; Grootendorst, M.R.; Fendler, W.P.; Costa, P.F.; Rischpler, C.; Praus, C.; et al. Intraoperative (68)Ga-PSMA Cerenkov Luminescence Imaging for Surgical Margins in Radical Prostatectomy: A Feasibility Study. J. Nucl. Med. 2020, 61, 1500-1506. [CrossRef]

126. Olde Heuvel, J.; de Wit-van der Veen, B.J.; van der Poel, H.G.; Bekers, E.M.; Grootendorst, M.R.; Vyas, K.N.; Slump, C.H.; Stokkel, M.P.M. (68)Ga-PSMA Cerenkov luminescence imaging in primary prostate cancer: First-in-man series. Eur. J. Nucl. Med. Mol. Imaging 2020, 47, 2624-2632. [CrossRef] [PubMed]

127. Darr, C.; Krafft, U.; Fendler, W.P.; Costa, P.F.; Barbato, F.; Praus, C.; Reis, H.; Hager, T.; Tschirdewahn, S.; Radtke, J.P.; et al. First-in-man intraoperative Cerenkov luminescence imaging for oligometastatic prostate cancer using (68)Ga-PSMA-11. Eur J. Nucl. Med. Mol. Imaging 2020, 47, 3194-3195. [CrossRef] [PubMed]

128. Olde Heuvel, J.; de Wit-van der Veen, B.J.; van der Poel, H.G.; van Leeuwen, P.J.; Bekers, E.M.; Grootendorst, M.R.; Vyas, K.N.; Slump, C.H.; Stokkel, M.P.M. Cerenkov Luminescence Imaging in prostate cancer: Not the only light that shines. J. Nucl. Med. 2021. [CrossRef] [PubMed]

129. Darr, C.; Fragoso Costa, P.; Kesch, C.; Krafft, U.; Pullen, L.; Harke, N.N.; Hess, J.; Szarvas, T.; Haubold, J.; Reis, H.; et al. Prostate specific membrane antigen-radio guided surgery using Cerenkov luminescence imaging-utilization of a short-pass filter to reduce technical pitfalls. Transl. Urol. 2021, 10, 3972-3985. [CrossRef]

130. Collamati, F.; van Oosterom, M.N.; Hadaschik, B.A.; Fragoso Costa, P.; Darr, C. Beta radioguided surgery: Towards routine implementation? Q. J. Nucl. Med. Mol. Imaging 2021, 65, 229-243. [CrossRef]

131. Van Leeuwen, F.W.B.; Cornelissen, B.; Caobelli, F.; Evangelista, L.; Rbah-Vidal, L.; Del Vecchio, S.; Xavier, C.; Barbet, J.; de Jong, M. Generation of fluorescently labeled tracers - which features influence the translational potential? EJNMMI Radiopharm. Chem. 2017, 2, 15. [CrossRef]

132. Maurer, T.; van Leeuwen, F.W.B.; Schottelius, M.; Wester, H.J.; Eiber, M. Entering the era of molecular-targeted precision surgery in recurrent prostate cancer. J. Nucl. Med. 2018. [CrossRef]

133. Lutje, S.; Heskamp, S.; Franssen, G.M.; Frielink, C.; Kip, A.; Hekman, M.; Fracasso, G.; Colombatti, M.; Herrmann, K.; Boerman, O.C.; et al. Development and characterization of a theranostic multimodal anti-PSMA targeting agent for imaging, surgical guidance, and targeted photodynamic therapy of PSMA-expressing tumors. Theranostics 2019, 9, 2924-2938. [CrossRef] [PubMed]

134. Derks, Y.H.W.; Lowik, D.; Sedelaar, J.P.M.; Gotthardt, M.; Boerman, O.C.; Rijpkema, M.; Lutje, S.; Heskamp, S. PSMA-targeting agents for radio- and fluorescence-guided prostate cancer surgery. Theranostics 2019, 9, 6824-6839. [CrossRef]

135. Hernandez Vargas, S.; Ghosh, S.C.; Azhdarinia, A. New Developments in Dual-Labeled Molecular Imaging Agents. J. Nucl. Med. 2019, 60, 459-465. [CrossRef]

136. Baranski, A.C.; Schafer, M.; Bauder-Wust, U.; Roscher, M.; Schmidt, J.; Stenau, E.; Simpfendorfer, T.; Teber, D.; Maier-Hein, L.; Hadaschik, B.; et al. PSMA-11-Derived Dual-Labeled PSMA Inhibitors for Preoperative PET Imaging and Precise FluorescenceGuided Surgery of Prostate Cancer. J. Nucl. Med. 2018, 59, 639-645. [CrossRef] [PubMed]

137. Baranski, A.C.; Schafer, M.; Bauder-Wust, U.; Wacker, A.; Schmidt, J.; Liolios, C.; Mier, W.; Haberkorn, U.; Eisenhut, M.; Kopka, K.; et al. Improving the Imaging Contrast of (68)Ga-PSMA-11 by Targeted Linker Design: Charged Spacer Moieties Enhance the Pharmacokinetic Properties. Bioconjug. Chem. 2017, 28, 2485-2492. [CrossRef]

138. Liolios, C.; Schafer, M.; Haberkorn, U.; Eder, M.; Kopka, K. Novel Bispecific PSMA/GRPr Targeting Radioligands with Optimized Pharmacokinetics for Improved PET Imaging of Prostate Cancer. Bioconjug. Chem. 2016, 27, 737-751. [CrossRef] [PubMed]

139. Eder, A.C.; Schafer, M.; Schmidt, J.; Bauder-Wust, U.; Roscher, M.; Leotta, K.; Haberkorn, U.; Kopka, K.; Eder, M. Rational Linker Design to Accelerate Excretion and Reduce Background Uptake of Peptidomimetic PSMA-Targeting Hybrid Molecules. J. Nucl. Med. 2021, 62, 1461-1467. [CrossRef] [PubMed]

140. Eder, A.C.; Omrane, M.A.; Stadlbauer, S.; Roscher, M.; Khoder, W.Y.; Gratzke, C.; Kopka, K.; Eder, M.; Meyer, P.T.; Jilg, C.A.; et al. The PSMA-11-derived hybrid molecule PSMA-914 specifically identifies prostate cancer by preoperative PET/CT and intraoperative fluorescence imaging. Eur. J. Nucl. Med. Mol. Imaging 2021, 48, 2057-2058. [CrossRef] [PubMed]

141. Schottelius, M.; Wurzer, A.; Wissmiller, K.; Beck, R.; Koch, M.; Gorpas, D.; Notni, J.; Buckle, T.; van Oosterom, M.N.; Steiger, K.; et al. Synthesis and Preclinical Characterization of the PSMA-Targeted Hybrid Tracer PSMA-I\&F for Nuclear and Fluorescence Imaging of Prostate Cancer. J. Nucl. Med. 2019, 60, 71-78. [CrossRef]

142. van Leeuwen, F.W.; van der Poel, H.G. Surgical Guidance in Prostate Cancer: "From Molecule to Man" Translations. Clin. Cancer Res. 2016, 22, 1304-1306. [CrossRef]

143. Van Leeuwen, F.W.B.; Schottelius, M.; Brouwer, O.R.; Vidal-Sicart, S.; Achilefu, S.; Klode, J.; Wester, H.J.; Buckle, T. Trending: Radioactive and Fluorescent Bimodal/Hybrid Tracers as Multiplexing Solutions for Surgical Guidance. J. Nucl. Med. 2020, 61, 13-19. [CrossRef] [PubMed]

144. Wang, X.; Luo, D.; Basilion, J.P. Photodynamic Therapy: Targeting Cancer Biomarkers for the Treatment of Cancers. Cancers 2021, 13, 992. [CrossRef] [PubMed]

145. Derks, Y.H.W.; Rijpkema, M.; Amatdjais-Groenen, H.I.V.; Kip, A.; Franssen, G.M.; Sedelaar, J.P.M.; Somford, D.M.; Simons, M.; Laverman, P.; Gotthardt, M.; et al. Photosensitizer-based multimodal PSMA-targeting ligands for intraoperative detection of prostate cancer. Theranostics 2021, 11, 1527-1541. [CrossRef] [PubMed] 
146. Kurth, J.; Krause, B.J.; Schwarzenbock, S.M.; Stegger, L.; Schafers, M.; Rahbar, K. External radiation exposure, excretion, and effective half-life in (177)Lu-PSMA-targeted therapies. EJNMMI Res. 2018, 8, 32. [CrossRef]

147. Dumelin, C.E.; Trussel, S.; Buller, F.; Trachsel, E.; Bootz, F.; Zhang, Y.; Mannocci, L.; Beck, S.C.; Drumea-Mirancea, M.; Seeliger, M.W.; et al. A portable albumin binder from a DNA-encoded chemical library. Angew. Chem. Int. Ed. Engl. 2008, 47, 3196-3201. [CrossRef] [PubMed]

148. Muller, C.; Struthers, H.; Winiger, C.; Zhernosekov, K.; Schibli, R. DOTA conjugate with an albumin-binding entity enables the first folic acid-targeted 177Lu-radionuclide tumor therapy in mice. J. Nucl. Med. 2013, 54, 124-131. [CrossRef] [PubMed]

149. Kelly, J.M.; Amor-Coarasa, A.; Nikolopoulou, A.; Wustemann, T.; Barelli, P.; Kim, D.; Williams, C., Jr.; Zheng, X.; Bi, C.; Hu, B.; et al. Dual-Target Binding Ligands with Modulated Pharmacokinetics for Endoradiotherapy of Prostate Cancer. J. Nucl. Med. 2017, 58, 1442-1449. [CrossRef] [PubMed]

150. Kelly, J.; Amor-Coarasa, A.; Ponnala, S.; Nikolopoulou, A.; Williams, C., Jr.; Schlyer, D.; Zhao, Y.; Kim, D.; Babich, J.W. Trifunctional PSMA-targeting constructs for prostate cancer with unprecedented localization to LNCaP tumors. Eur. J. Nucl. Med. Mol. Imaging 2018, 45, 1841-1851. [CrossRef]

151. Kelly, J.M.; Amor-Coarasa, A.; Ponnala, S.; Nikolopoulou, A.; Williams, C., Jr.; DiMagno, S.G.; Babich, J.W. Albumin-Binding PSMA Ligands: Implications for Expanding the Therapeutic Window. J. Nucl. Med. 2019, 60, 656-663. [CrossRef] [PubMed]

152. Benesova, M.; Umbricht, C.A.; Schibli, R.; Muller, C. Albumin-Binding PSMA Ligands: Optimization of the Tissue Distribution Profile. Mol. Pharm. 2018, 15, 934-946. [CrossRef]

153. Umbricht, C.A.; Benesova, M.; Schibli, R.; Muller, C. Preclinical Development of Novel PSMA-Targeting Radioligands: Modulation of Albumin-Binding Properties To Improve Prostate Cancer Therapy. Mol. Pharm. 2018, 15, 2297-2306. [CrossRef]

154. Borgna, F.; Deberle, L.M.; Cohrs, S.; Schibli, R.; Muller, C. Combined Application of Albumin-Binding [(177)Lu]Lu-PSMA-ALB-56 and Fast-Cleared PSMA Inhibitors: Optimization of the Pharmacokinetics. Mol. Pharm. 2020, 17, 2044-2053. [CrossRef]

155. Kramer, V.; Fernandez, R.; Lehnert, W.; Jimenez-Franco, L.D.; Soza-Ried, C.; Eppard, E.; Ceballos, M.; Meckel, M.; Benesova, M.; Umbricht, C.A.; et al. Biodistribution and dosimetry of a single dose of albumin-binding ligand [(177)Lu]Lu-PSMA-ALB-56 in patients with mCRPC. Eur. J. Nucl. Med. Mol. Imaging 2021, 48, 893-903. [CrossRef]

156. Deberle, L.M.; Benesova, M.; Umbricht, C.A.; Borgna, F.; Buchler, M.; Zhernosekov, K.; Schibli, R.; Muller, C. Development of a new class of PSMA radioligands comprising ibuprofen as an albumin-binding entity. Theranostics 2020, 10, 1678-1693. [CrossRef]

157. Deberle, L.M.; Tschan, V.J.; Borgna, F.; Sozzi-Guo, F.; Bernhardt, P.; Schibli, R.; Muller, C. Albumin-Binding PSMA Radioligands: Impact of Minimal Structural Changes on the Tissue Distribution Profile. Molecules 2020, 25, 542. [CrossRef] [PubMed]

158. Tschan, V.J.; Borgna, F.; Schibli, R.; Muller, C. Impact of the mouse model and molar amount of injected ligand on the tissue distribution profile of PSMA radioligands. Eur. J. Nucl. Med. Mol. Imaging 2021. [CrossRef] [PubMed]

159. Sancho, V.; Di Florio, A.; Moody, T.W.; Jensen, R.T. Bombesin receptor-mediated imaging and cytotoxicity: Review and current status. Curr Drug Deliv 2011, 8, 79-134. [CrossRef]

160. Mansi, R.; Nock, B.A.; Dalm, S.U.; Busstra, M.B.; van Weerden, W.M.; Maina, T. Radiolabeled Bombesin Analogs. Cancers 2021, 13, 766. [CrossRef]

161. Rybalov, M.; Ananias, H.J.; Hoving, H.D.; van der Poel, H.G.; Rosati, S.; de Jong, I.J. PSMA, EpCAM, VEGF and GRPR as imaging targets in locally recurrent prostate cancer after radiotherapy. Int J. Mol. Sci 2014, 15, 6046-6061. [CrossRef]

162. Schollhammer, R.; De Clermont Gallerande, H.; Yacoub, M.; Quintyn Ranty, M.L.; Barthe, N.; Vimont, D.; Hindie, E.; Fernandez, P.; Morgat, C. Comparison of the radiolabeled PSMA-inhibitor (111)In-PSMA-617 and the radiolabeled GRP-R antagonist (111)In-RM2 in primary prostate cancer samples. EJNMMI Res. 2019, 9, 52. [CrossRef] [PubMed]

163. Minamimoto, R.; Hancock, S.; Schneider, B.; Chin, F.T.; Jamali, M.; Loening, A.; Vasanawala, S.; Gambhir, S.S.; Iagaru, A. Pilot Comparison of (6)(8)Ga-RM2 PET and (6)(8)Ga-PSMA-11 PET in Patients with Biochemically Recurrent Prostate Cancer. J. Nucl. Med. 2016, 57, 557-562. [CrossRef]

164. Hoberuck, S.; Michler, E.; Wunderlich, G.; Lock, S.; Holscher, T.; Froehner, M.; Braune, A.; Ivan, P.; Seppelt, D.; Zophel, K.; et al. 68Ga-RM2 PET in PSMA- positive and -negative prostate cancer patients. Nuklearmedizin 2019, 58, 352-362. [CrossRef]

165. Fassbender, T.F.; Schiller, F.; Zamboglou, C.; Drendel, V.; Kiefer, S.; Jilg, C.A.; Grosu, A.L.; Mix, M. Voxel-based comparison of [(68)Ga]Ga-RM2-PET/CT and [(68)Ga]Ga-PSMA-11-PET/CT with histopathology for diagnosis of primary prostate cancer. EJNMMI Res. 2020, 10, 62. [CrossRef]

166. Baratto, L.; Song, H.; Duan, H.; Hatami, N.; Bagshaw, H.P.; Buyyounouski, M.; Hancock, S.; Shah, S.; Srinivas, S.; Swift, P.; et al. PSMA- and GRPR-Targeted PET: Results from 50 Patients with Biochemically Recurrent Prostate Cancer. J. Nucl. Med. 2021, 62, 1545-1549. [CrossRef]

167. Mapelli, P.; Ghezzo, S.; Samanes Gajate, A.M.; Preza, E.; Brembilla, G.; Cucchiara, V.; Ahmed, N.; Bezzi, C.; Presotto, L.; Bettinardi, V.; et al. Preliminary Results of an Ongoing Prospective Clinical Trial on the Use of (68)Ga-PSMA and (68)Ga-DOTARM2 PET/MRI in Staging of High-Risk Prostate Cancer Patients. Diagnostics 2021, 11, 68. [CrossRef]

168. Iagaru, A. Will GRPR Compete with PSMA as a Target in Prostate Cancer? J. Nucl. Med. 2017, 58, 1883-1884. [CrossRef]

169. Reubi, J.C.; Maecke, H.R. Approaches to Multireceptor Targeting: Hybrid Radioligands, Radioligand Cocktails, and Sequential Radioligand Applications. J. Nucl. Med. 2017, 58, 10S-16S. [CrossRef] [PubMed]

170. Yan, Y.; Chen, X. Peptide heterodimers for molecular imaging. Amino Acids 2011, 41, 1081-1092. [CrossRef] [PubMed] 
171. Liolios, C.; Sachpekidis, C.; Schafer, M.; Kopka, K. Bispecific radioligands targeting prostate-specific membrane antigen and gastrin-releasing peptide receptors on the surface of prostate cancer cells. J. Label. Comp. Radiopharm. 2019, 62, 510-522. [CrossRef] [PubMed]

172. Eder, M.; Schafer, M.; Bauder-Wust, U.; Haberkorn, U.; Eisenhut, M.; Kopka, K. Preclinical evaluation of a bispecific low-molecular heterodimer targeting both PSMA and GRPR for improved PET imaging and therapy of prostate cancer. Prostate 2014, 74, 659-668. [CrossRef] [PubMed]

173. Cheng, C.; Pan, L.; Dimitrakopoulou-Strauss, A.; Schafer, M.; Wangler, C.; Wangler, B.; Haberkorn, U.; Strauss, L.G. Comparison between 68Ga-bombesin (68Ga-BZH3) and the cRGD tetramer 68Ga-RGD4 studies in an experimental nude rat model with a neuroendocrine pancreatic tumor cell line. EJNMMI Res. 2011, 1, 34. [CrossRef]

174. Strauss, L.G.; Koczan, D.; Seiz, M.; Tuettenberg, J.; Schmieder, K.; Pan, L.; Cheng, C.; Dimitrakopoulou-Strauss, A. Correlation of the Ga-68-bombesin analog Ga-68-BZH3 with receptors expression in gliomas as measured by quantitative dynamic positron emission tomography (dPET) and gene arrays. Mol. Imaging Biol. 2012, 14, 376-383. [CrossRef]

175. Bandari, R.P.; Jiang, Z.; Reynolds, T.S.; Bernskoetter, N.E.; Szczodroski, A.F.; Bassuner, K.J.; Kirkpatrick, D.L.; Rold, T.L.; Sieckman, G.L.; Hoffman, T.J.; et al. Synthesis and biological evaluation of copper-64 radiolabeled [DUPA-6-Ahx-(NODAGA)-5Ava-BBN(7-14)NH2], a novel bivalent targeting vector having affinity for two distinct biomarkers (GRPr/PSMA) of prostate cancer. Nucl. Med. Biol. 2014, 41, 355-363. [CrossRef]

176. Bandari, R.P.; Lewis, M.R.; Smith, C.J. Synthesis and Evaluation of [DUPA-6-Ahx-Lys (DOTA)-6-Ahx-RM2], a Novel, Bivalent Targeting Ligand for GRPr/PSMA Biomarkers of Prostate Cancer. Chem. Biol. Lett. 2018, 5, 14.

177. Bandari, R.P.; Carmack, T.L.; Malhotra, A.; Watkinson, L.; Fergason Cantrell, E.A.; Lewis, M.R.; Smith, C.J. Development of Heterobivalent Theranostic Probes Having High Affinity/Selectivity for the GRPR/PSMA. J. Med. Chem. 2021, 64, 2151-2166. [CrossRef] [PubMed]

178. Mendoza-Figueroa, M.J.; Escudero-Castellanos, A.; Ramirez-Nava, G.J.; Ocampo-García, B.E.; Santos-Cuevas, C.L.; FerroFlores, G.; Pedraza-Lopez, M.; Avila-Rodriguez, M.A. Preparation and preclinical evaluation of 68Ga-iPSMA-BN as a potential heterodimeric radiotracer for PET-imaging of prostate cancer. J. Radioanal. Nucl. Chem. 2018, 318, 2097-2105. [CrossRef]

179. Escudero-Castellanos, A.; Ocampo-Garcia, B.; Ferro-Flores, G.; Santos-Cuevas, C.; Morales-Avila, E.; Luna-Gutierrez, M.; IsaacOlive, K. Synthesis and preclinical evaluation of the 177Lu-DOTA-PSMA(inhibitor)-Lys3-bombesin heterodimer designed as a radiotheranostic probe for prostate cancer. Nucl. Med. Commun. 2019, 40, 278-286. [CrossRef]

180. Rivera-Bravo, B.; Ramirez-Nava, G.; Mendoza-Figueroa, M.J.; Ocampo-Garcia, B.; Ferro-Flores, G.; Avila-Rodriguez, M.A.; Santos-Cuevas, C. [(68)Ga]Ga-iPSMA-Lys(3)-Bombesin: Biokinetics, dosimetry and first patient PET/CT imaging. Nucl. Med. Biol. 2021, 96-97, 54-60. [CrossRef] [PubMed]

181. Mitran, B.; Varasteh, Z.; Abouzayed, A.; Rinne, S.S.; Puuvuori, E.; De Rosa, M.; Larhed, M.; Tolmachev, V.; Orlova, A.; Rosenstrom, U. Bispecific GRPR-Antagonistic Anti-PSMA/GRPR Heterodimer for PET and SPECT Diagnostic Imaging of Prostate Cancer. Cancers 2019, 11, 371. [CrossRef]

182. Lundmark, F.; Abouzayed, A.; Mitran, B.; Rinne, S.S.; Varasteh, Z.; Larhed, M.; Tolmachev, V.; Rosenstrom, U.; Orlova, A. Heterodimeric Radiotracer Targeting PSMA and GRPR for Imaging of Prostate Cancer-Optimization of the Affinity towards PSMA by Linker Modification in Murine Model. Pharmaceutics 2020, 12. [CrossRef] [PubMed]

183. Abouzayed, A.; Yim, C.B.; Mitran, B.; Rinne, S.S.; Tolmachev, V.; Larhed, M.; Rosenstrom, U.; Orlova, A. Synthesis and Preclinical Evaluation of Radio-Iodinated GRPR/PSMA Bispecific Heterodimers for the Theranostics Application in Prostate Cancer. Pharmaceutics 2019, 11, 358. [CrossRef] [PubMed]

184. Shallal, H.M.; Minn, I.; Banerjee, S.R.; Lisok, A.; Mease, R.C.; Pomper, M.G. Heterobivalent agents targeting PSMA and integrin-alphavbeta3. Bioconjug Chem. 2014, 25, 393-405. [CrossRef]

185. Liolios, C.; Sachpekidis, C.; Kolocouris, A.; Dimitrakopoulou-Strauss, A.; Bouziotis, P. PET Diagnostic Molecules Utilizing Multimeric Cyclic RGD Peptide Analogs for Imaging Integrin alphavbeta3 Receptors. Molecules 2021, 26, 792. [CrossRef] [PubMed]

186. Maschauer, S.; Einsiedel, J.; Haubner, R.; Hocke, C.; Ocker, M.; Hubner, H.; Kuwert, T.; Gmeiner, P.; Prante, O. Labeling and glycosylation of peptides using click chemistry: A general approach to (18)F-glycopeptides as effective imaging probes for positron emission tomography. Angew. Chem. Int. Ed. Engl. 2010, 49, 976-979. [CrossRef] [PubMed]

187. Potemkin, R.; Strauch, B.; Kuwert, T.; Prante, O.; Maschauer, S. Development of (18)F-Fluoroglycosylated PSMA-Ligands with Improved Renal Clearance Behavior. Mol. Pharm. 2020, 17, 933-943. [CrossRef]

188. Greifenstein, L.; Engelbogen, N.; Lahnif, H.; Sinnes, J.P.; Bergmann, R.; Bachmann, M.; Rosch, F. Synthesis, Labeling and Preclinical Evaluation of a Squaric Acid Containing PSMA Inhibitor Labeled with (68) Ga: A Comparison with PSMA-11 and PSMA-617. ChemMedChem 2020, 15, 695-704. [CrossRef]

189. Grus, T.; Lahnif, H.; Klasen, B.; Moon, E.S.; Greifenstein, L.; Roesch, F. Squaric Acid-Based Radiopharmaceuticals for Tumor Imaging and Therapy. Bioconjug. Chem. 2021, 32, 1223-1231. [CrossRef]

190. Schirrmacher, R.; Bradtmoller, G.; Schirrmacher, E.; Thews, O.; Tillmanns, J.; Siessmeier, T.; Buchholz, H.G.; Bartenstein, P.; Wangler, B.; Niemeyer, C.M.; et al. 18F-labeling of peptides by means of an organosilicon-based fluoride acceptor. Angew Chem. Int. Ed. Engl. 2006, 45, 6047-6050. [CrossRef] [PubMed]

191. Wurzer, A.; Di Carlo, D.; Schmidt, A.; Beck, R.; Eiber, M.; Schwaiger, M.; Wester, H.J. Radiohybrid Ligands: A Novel Tracer Concept Exemplified by (18)F- or (68)Ga-Labeled rhPSMA Inhibitors. J. Nucl. Med. 2020, 61, 735-742. [CrossRef] [PubMed] 
192. Eiber, M.; Kroenke, M.; Wurzer, A.; Ulbrich, L.; Jooss, L.; Maurer, T.; Horn, T.; Schiller, K.; Langbein, T.; Buschner, G.; et al. (18)F-rhPSMA-7 PET for the Detection of Biochemical Recurrence of Prostate Cancer After Radical Prostatectomy. J. Nucl. Med. 2020, 61, 696-701. [CrossRef] [PubMed]

193. Oh, S.W.; Wurzer, A.; Teoh, E.J.; Oh, S.; Langbein, T.; Kronke, M.; Herz, M.; Kropf, S.; Wester, H.J.; Weber, W.A.; et al. Quantitative and Qualitative Analyses of Biodistribution and PET Image Quality of a Novel Radiohybrid PSMA, (18)F-rhPSMA-7, in Patients with Prostate Cancer. J. Nucl. Med. 2020, 61, 702-709. [CrossRef]

194. Kroenke, M.; Mirzoyan, L.; Horn, T.; Peeken, J.C.; Wurzer, A.; Wester, H.J.; Makowski, M.; Weber, W.A.; Eiber, M.; Rauscher, I. Matched-Pair Comparison of (68)Ga-PSMA-11 and (18)F-rhPSMA-7 PET/CT in Patients with Primary and Biochemical Recurrence of Prostate Cancer: Frequency of Non-Tumor-Related Uptake and Tumor Positivity. J. Nucl. Med. 2021, 62, 1082-1088. [CrossRef]

195. Wurzer, A.; Di Carlo, D.; Herz, M.; Richter, A.; Robu, S.; Schirrmacher, R.; Mascarin, A.; Weber, W.; Eiber, M.; Schwaiger, M.; et al. Automated synthesis of [(18)F]Ga-rhPSMA-7/-7.3: Results, quality control and experience from more than 200 routine productions. EJNMMI Radiopharm. Chem. 2021, 6, 4. [CrossRef] [PubMed]

196. Rauscher, I.; Karimzadeh, A.; Schiller, K.; Horn, T.; D'Alessandria, C.; Franz, C.; Worther, H.; Nguyen, N.; Combs, S.E.; Weber, W.A.; et al. Detection efficacy of (18)F-rhPSMA-7.3 PET/CT and impact on patient management in patients with biochemical recurrence of prostate cancer after radical prostatectomy and prior to potential salvage treatment. J. Nucl. Med. 2021. [CrossRef]

197. Malaspina, S.; Oikonen, V.; Kuisma, A.; Ettala, O.; Mattila, K.; Bostrom, P.J.; Minn, H.; Kalliokoski, K.; Postema, E.J.; Miller, M.P.; et al. Kinetic analysis and optimisation of (18)F-rhPSMA-7.3 PET imaging of prostate cancer. Eur J. Nucl. Med. Mol. Imaging 2021, 48, 3723-3731. [CrossRef]

198. Luurtsema, G.; Pichler, V.; Bongarzone, S.; Seimbille, Y.; Elsinga, P.; Gee, A.; Vercouillie, J. EANM guideline for harmonisation on molar activity or specific activity of radiopharmaceuticals: Impact on safety and imaging quality. EJNMMI Radiopharm. Chem. 2021, 6, 34. [CrossRef]

199. Langbein, T.; Wurzer, A.; Gafita, A.; Robertson, A.; Wang, H.; Arcay, A.; Herz, M.; Wester, H.J.; Weber, W.A.; Eiber, M. The Influence of Specific Activity on the Biodistribution of (18)F-rhPSMA-7.3: A Retrospective Analysis of Clinical Positron Emission Tomography Data. J. Nucl. Med. 2021. [CrossRef] [PubMed]

200. Kuo, H.T.; Lepage, M.L.; Lin, K.S.; Pan, J.; Zhang, Z.; Liu, Z.; Pryyma, A.; Zhang, C.; Merkens, H.; Roxin, A.; et al. One-Step (18)F-Labeling and Preclinical Evaluation of Prostate-Specific Membrane Antigen Trifluoroborate Probes for Cancer Imaging. J. Nucl. Med. 2019, 60, 1160-1166. [CrossRef] [PubMed]

201. Lepage, M.L.; Kuo, H.T.; Roxin, A.; Huh, S.; Zhang, Z.; Kandasamy, R.; Merkens, H.; Kumlin, J.O.; Limoges, A.; Zeisler, S.K.; et al. Toward (18) F-Labeled Theranostics: A Single Agent that Can Be Labeled with (18) F, (64) Cu, or (177) Lu. Chembiochem 2020, 21, 943-947. [CrossRef] [PubMed]

202. Boswell, C.A.; Sun, X.; Niu, W.; Weisman, G.R.; Wong, E.H.; Rheingold, A.L.; Anderson, C.J. Comparative in vivo stability of copper-64-labeled cross-bridged and conventional tetraazamacrocyclic complexes. J. Med. Chem. 2004, 47, 1465-1474. [CrossRef] [PubMed]

203. Han, X.D.; Liu, C.; Liu, F.; Xie, Q.H.; Liu, T.L.; Guo, X.Y.; Xu, X.X.; Yang, X.; Zhu, H.; Yang, Z. (64)Cu-PSMA-617: A novel PSMA-targeted radio-tracer for PET imaging in gastric adenocarcinoma xenografted mice model. Oncotarget 2017, 8, 74159-74169. [CrossRef] [PubMed]

204. Avila-Rodriguez, M.A.; Rios, C.; Carrasco-Hernandez, J.; Manrique-Arias, J.C.; Martinez-Hernandez, R.; Garcia-Perez, F.O.; Jalilian, A.R.; Martinez-Rodriguez, E.; Romero-Pina, M.E.; Diaz-Ruiz, A. Biodistribution and radiation dosimetry of [(64)Cu]copper dichloride: First-in-human study in healthy volunteers. EJNMMI Res. 2017, 7, 98. [CrossRef] [PubMed]

205. Hoberuck, S.; Wunderlich, G.; Michler, E.; Holscher, T.; Walther, M.; Seppelt, D.; Platzek, I.; Zophel, K.; Kotzerke, J. Dualtime-point (64) Cu-PSMA-617-PET/CT in patients suffering from prostate cancer. J. Label. Comp. Radiopharm 2019, 62, 523-532. [CrossRef] [PubMed]

206. Eychenne, R.; Cherel, M.; Haddad, F.; Guerard, F.; Gestin, J.F. Overview of the Most Promising Radionuclides for Targeted Alpha Therapy: The "Hopeful Eight". Pharmaceutics 2021, 13, 906. [CrossRef]

207. Duchemin, C.; Ramos, J.P.; Stora, T.; Ahmed, E.; Aubert, E.; Audouin, N.; Barbero, E.; Barozier, V.; Bernardes, A.P.; Bertreix, P.; et al. CERN-MEDICIS: A Review Since Commissioning in 2017. Front. Med. 2021, 8, 693682. [CrossRef]

208. Radchenko, V.; Morgenstern, A.; Jalilian, A.R.; Ramogida, C.F.; Cutler, C.; Duchemin, C.; Hoehr, C.; Haddad, F.; Bruchertseifer, F.; Gausemel, H.; et al. Production and Supply of alpha-Particle-Emitting Radionuclides for Targeted alpha-Therapy. J. Nucl. Med. 2021, 62, 1495-1503. [CrossRef]

209. Sathekge, M.; Bruchertseifer, F.; Knoesen, O.; Reyneke, F.; Lawal, I.; Lengana, T.; Davis, C.; Mahapane, J.; Corbett, C.; Vorster, M.; et al. (225)Ac-PSMA-617 in chemotherapy-naive patients with advanced prostate cancer: A pilot study. Eur. J. Nucl. Med. Mol. Imaging 2019, 46, 129-138. [CrossRef] [PubMed]

210. Sathekge, M.; Bruchertseifer, F.; Vorster, M.; Lawal, I.O.; Knoesen, O.; Mahapane, J.; Davis, C.; Reyneke, F.; Maes, A.; Kratochwil, C.; et al. Predictors of Overall and Disease-Free Survival in Metastatic Castration-Resistant Prostate Cancer Patients Receiving (225)Ac-PSMA-617 Radioligand Therapy. J. Nucl. Med. 2020, 61, 62-69. [CrossRef] [PubMed] 
211. Sathekge, M.M.; Bruchertseifer, F.; Lawal, I.O.; Vorster, M.; Knoesen, O.; Lengana, T.; Boshomane, T.G.; Mokoala, K.K.; Morgenstern, A. Treatment of brain metastases of castration-resistant prostate cancer with (225)Ac-PSMA-617. Eur J. Nucl. Med. Mol. Imaging 2019, 46, 1756-1757. [CrossRef] [PubMed]

212. Khreish, F.; Ebert, N.; Ries, M.; Maus, S.; Rosar, F.; Bohnenberger, H.; Stemler, T.; Saar, M.; Bartholoma, M.; Ezziddin, S. (225)AcPSMA-617/(177)Lu-PSMA-617 tandem therapy of metastatic castration-resistant prostate cancer: Pilot experience. Eur. J. Nucl. Med. Mol. Imaging 2020, 47, 721-728. [CrossRef]

213. Ilhan, H.; Gosewisch, A.; Boning, G.; Volter, F.; Zacherl, M.; Unterrainer, M.; Bartenstein, P.; Todica, A.; Gildehaus, F.J. Response to (225)Ac-PSMA-I\&T after failure of long-term (177)Lu-PSMA RLT in mCRPC. Eur J. Nucl. Med. Mol. Imaging 2021, 48, 1262-1263. [CrossRef]

214. Rosar, F.; Hau, F.; Bartholoma, M.; Maus, S.; Stemler, T.; Linxweiler, J.; Ezziddin, S.; Khreish, F. Molecular imaging and biochemical response assessment after a single cycle of [(225)Ac]Ac-PSMA-617/[(177)Lu]Lu-PSMA-617 tandem therapy in mCRPC patients who have progressed on [(177)Lu]Lu-PSMA-617 monotherapy. Theranostics 2021, 11, 4050-4060. [CrossRef]

215. Sathekge, M.M.; Bruchertseifer, F.; Vorster, M.; Morgenstern, A.; Lawal, I.O. Global experience with PSMA-based alpha therapy in prostate cancer. Eur J. Nucl. Med. Mol. Imaging 2021. [CrossRef]

216. Roscher, M.; Bakos, G.; Benesova, M. Atomic Nanogenerators in Targeted Alpha Therapies: Curie's Legacy in Modern Cancer Management. Pharmaceuticals 2020, 13, 76. [CrossRef] [PubMed]

217. Feuerecker, B.; Tauber, R.; Knorr, K.; Heck, M.; Beheshti, A.; Seidl, C.; Bruchertseifer, F.; Pickhard, A.; Gafita, A.; Kratochwil, C.; et al. Activity and Adverse Events of Actinium-225-PSMA-617 in Advanced Metastatic Castration-resistant Prostate Cancer After Failure of Lutetium-177-PSMA. Eur. Urol. 2021, 79, 343-350. [CrossRef] [PubMed]

218. Verburg, F.A.; Nonnekens, J.; Konijnenberg, M.W.; de Jong, M. To go where no one has gone before: The necessity of radiobiology studies for exploration beyond the limits of the "Holy Gray" in radionuclide therapy. Eur. J. Nucl. Med. Mol. Imaging 2021, 48, 2680-2682. [CrossRef] [PubMed]

219. Dhiantravan, N.; Hofman, M.S.; Ravi Kumar, A.S. Actinium-225 Prostate-specific Membrane Antigen Theranostics: Will alpha Beat beta? Eur. Urol. 2021, 79, 351-352. [CrossRef]

220. Aerts, A.; Eberlein, U.; Holm, S.; Hustinx, R.; Konijnenberg, M.; Strigari, L.; van Leeuwen, F.W.B.; Glatting, G.; Lassmann, M. EANM position paper on the role of radiobiology in nuclear medicine. Eur. J. Nucl. Med. Mol. Imaging 2021, 48, 3365-3377. [CrossRef]

221. Pouget, J.P.; Constanzo, J. Revisiting the Radiobiology of Targeted Alpha Therapy. Front. Med. 2021, 8, 692436. [CrossRef]

222. Kelly, J.M.; Amor-Coarasa, A.; Sweeney, E.; Wilson, J.J.; Causey, P.W.; Babich, J. A Consensus Time for Performing Quality Control of 225Ac-Labeled Radiopharmaceuticals. Res. Sq. 2020. [CrossRef]

223. Hooijman, E.L.; Chalashkan, Y.; Ling, S.W.; Kahyargil, F.F.; Segbers, M.; Bruchertseifer, F.; Morgenstern, A.; Seimbille, Y.; Koolen, S.L.W.; Brabander, T.; et al. Development of [(225)Ac]Ac-PSMA-I\&T for Targeted Alpha Therapy According to GMP Guidelines for Treatment of mCRPC. Pharmaceutics 2021, 13, 715. [CrossRef]

224. Dumond, A.R.S.; Rodnick, M.E.; Piert, M.R.; Scott, P.J.H. Synthesis of 225Ac-PSMA-617 for preclinical use. Curr. Radiopharm 2021. [CrossRef] [PubMed]

225. Pretze, M.; Kunkel, F.; Runge, R.; Freudenberg, R.; Braune, A.; Hartmann, H.; Schwarz, U.; Brogsitter, C.; Kotzerke, J. Ac-EAZY! Towards GMP-Compliant Module Syntheses of (225)Ac-Labeled Peptides for Clinical Application. Pharmaceuticals 2021, 14, 652. [CrossRef]

226. Thakral, P.; Simecek, J.; Marx, S.; Kumari, J.; Pant, V.; Sen, I.B. In-House Preparation and Quality Control of Ac-225 ProstateSpecific Membrane Antigen-617 for the Targeted Alpha Therapy of Castration-Resistant Prostate Carcinoma. Indian J. Nucl. Med. 2021, 36, 114-119. [CrossRef] [PubMed]

227. Neels, O.; Patt, M.; Decristoforo, C. Radionuclides: Medicinal products or rather starting materials? EJNMMI Radiopharm Chem. 2019, 4, 22. [CrossRef]

228. Decristoforo, C.; Neels, O.; Patt, M. Emerging Radionuclides in a Regulatory Framework for Medicinal Products - How Do They Fit? Front. Med. 2021, 8, 678452. [CrossRef] [PubMed]

229. Kiess, A.P.; Minn, I.; Vaidyanathan, G.; Hobbs, R.F.; Josefsson, A.; Shen, C.; Brummet, M.; Chen, Y.; Choi, J.; Koumarianou, E.; et al. (2S)-2-(3-(1-Carboxy-5-(4-211At-Astatobenzamido)Pentyl)Ureido)-Pentanedioic Acid for PSMATargeted alpha-Particle Radiopharmaceutical Therapy. J. Nucl. Med. 2016, 57, 1569-1575. [CrossRef]

230. Mease, R.C.; Kang, C.; Kumar, V.; Ray, S.; Minn, I.L.; Brummet, M.; Gabrielson, K.; Feng, Y.; Park, A.; Kiess, A.; et al. An improved (211)At-labeled agent for PSMA-targeted alpha therapy. J. Nucl. Med. 2021. [CrossRef] [PubMed]

231. Lindegren, S.; Albertsson, P.; Back, T.; Jensen, H.; Palm, S.; Aneheim, E. Realizing Clinical Trials with Astatine-211: The Chemistry Infrastructure. Cancer Biother. Radiopharm. 2020, 35, 425-436. [CrossRef] [PubMed]

232. Feng, Y.; Zalutsky, M.R. Production, purification and availability of (211)At: Near term steps towards global access. Nucl. Med. Biol. 2021, 100-101, 12-23. [CrossRef]

233. Zia, N.A.; Cullinane, C.; Van Zuylekom, J.K.; Waldeck, K.; McInnes, L.E.; Buncic, G.; Haskali, M.B.; Roselt, P.D.; Hicks, R.J.; Donnelly, P.S. A Bivalent Inhibitor of Prostate Specific Membrane Antigen Radiolabeled with Copper-64 with High Tumor Uptake and Retention. Angew. Chem. Int. Ed. Engl. 2019, 58, 14991-14994. [CrossRef] 
234. McInnes, L.E.; Cullinane, C.; Roselt, P.D.; Jackson, S.; Blyth, B.J.; van Dam, E.M.; Zia, N.A.; Harris, M.J.; Hicks, R.J.; Donnelly, P.S. Therapeutic Efficacy of a Bivalent Inhibitor of Prostate-Specific Membrane Antigen Labeled with (67)Cu. J. Nucl. Med. 2021, 62, 829-832. [CrossRef]

235. Kelly, J.M.; Ponnala, S.; Amor-Coarasa, A.; Zia, N.A.; Nikolopoulou, A.; Williams, C., Jr.; Schlyer, D.J.; DiMagno, S.G.; Donnelly, P.S.; Babich, J.W. Preclinical Evaluation of a High-Affinity Sarcophagine-Containing PSMA Ligand for (64)Cu/(67)CuBased Theranostics in Prostate Cancer. Mol. Pharm. 2020, 17, 1954-1962. [CrossRef]

236. McNeil, B.L.; Robertson, A.K.H.; Fu, W.; Yang, H.; Hoehr, C.; Ramogida, C.F.; Schaffer, P. Production, purification, and radiolabeling of the (203) $\mathrm{Pb} /(212) \mathrm{Pb}$ theranostic pair. EJNMMI Radiopharm. Chem. 2021, 6, 6. [CrossRef] [PubMed]

237. Dos Santos, J.C.; Schafer, M.; Bauder-Wust, U.; Lehnert, W.; Leotta, K.; Morgenstern, A.; Kopka, K.; Haberkorn, U.; Mier, W.; Kratochwil, C. Development and dosimetry of (203)Pb/(212)Pb-labelled PSMA ligands: Bringing "the lead" into PSMA-targeted alpha therapy? Eur. J. Nucl. Med. Mol. Imaging 2019, 46, 1081-1091. [CrossRef] [PubMed]

238. Stenberg, V.Y.; Juzeniene, A.; Chen, Q.; Yang, X.; Bruland, O.S.; Larsen, R.H. Preparation of the alpha-emitting prostate-specific membrane antigen targeted radioligand [(212) Pb]Pb-NG001 for prostate cancer. J. Label. Comp. Radiopharm. 2020, 63, 129-143. [CrossRef]

239. Stenberg, V.Y.; Juzeniene, A.; Bruland, O.S.; Larsen, R.H. In situ Generated ${ }^{212} \mathrm{~Pb}-\mathrm{PSMA}$ Ligand in a ${ }^{224}$ Ra-Solution for Dual Targeting of Prostate Cancer Sclerotic Stroma and PSMA-positive Cells. Curr. Radiopharm. 2020, 13, 130-141. [CrossRef] [PubMed]

240. Stenberg, V.Y.; Larsen, R.H.; Ma, L.W.; Peng, Q.; Juzenas, P.; Bruland, O.S.; Juzeniene, A. Evaluation of the PSMA-Binding Ligand (212)Pb-NG001 in Multicellular Tumour Spheroid and Mouse Models of Prostate Cancer. Int. J. Mol. Sci. 2021, 22, 815. [CrossRef]

241. De Kruijff, R.M.; Wolterbeek, H.T.; Denkova, A.G. A Critical Review of Alpha Radionuclide Therapy-How to Deal with Recoiling Daughters? Pharmaceuticals 2015, 8, 321-336. [CrossRef]

242. Muller, C.; Zhernosekov, K.; Koster, U.; Johnston, K.; Dorrer, H.; Hohn, A.; van der Walt, N.T.; Turler, A.; Schibli, R. A unique matched quadruplet of terbium radioisotopes for PET and SPECT and for alpha- and beta- radionuclide therapy: An in vivo proof-of-concept study with a new receptor-targeted folate derivative. J. Nucl. Med. 2012, 53, 1951-1959. [CrossRef]

243. Umbricht, C.A.; Koster, U.; Bernhardt, P.; Gracheva, N.; Johnston, K.; Schibli, R.; van der Meulen, N.P.; Muller, C. Alpha-PET for Prostate Cancer: Preclinical investigation using (149)Tb-PSMA-617. Sci. Rep. 2019, 9, 17800. [CrossRef]

244. Muller, C.; Umbricht, C.A.; Gracheva, N.; Tschan, V.J.; Pellegrini, G.; Bernhardt, P.; Zeevaart, J.R.; Koster, U.; Schibli, R.; van der Meulen, N.P. Terbium-161 for PSMA-targeted radionuclide therapy of prostate cancer. Eur J. Nucl. Med. Mol. Imaging 2019, 46, 1919-1930. [CrossRef]

245. Bernhardt, P.; Svensson, J.; Hemmingsson, J.; van der Meulen, N.P.; Zeevaart, J.R.; Konijnenberg, M.W.; Muller, C.; Kindblom, J. Dosimetric Analysis of the Short-Ranged Particle Emitter (161)Tb for Radionuclide Therapy of Metastatic Prostate Cancer. Cancers 2021, 13, 11. [CrossRef]

246. Palmer, T.L.; Tkacz-Stachowska, K.; Skartlien, R.; Omar, N.; Hassfjell, S.; Mjos, A.; Bergvoll, J.; Brevik, E.M.; Hjelstuen, O. Microdosimetry modeling with auger emitters in generalized cell geometry. Phys. Med. Biol. 2021, 66. [CrossRef]

247. Muller, C.; Domnanich, K.A.; Umbricht, C.A.; van der Meulen, N.P. Scandium and terbium radionuclides for radiotheranostics: Current state of development towards clinical application. Br. J. Radiol. 2018, 91, 20180074. [CrossRef] [PubMed]

248. Naskar, N.; Lahiri, S. Theranostic Terbium Radioisotopes: Challenges in Production for Clinical Application. Front. Med. 2021, 8, 675014. [CrossRef] [PubMed]

249. Vazquez, S.M.; Endepols, H.; Fischer, T.; Tawadros, S.G.; Hohberg, M.; Zimmermanns, B.; Dietlein, F.; Neumaier, B.; Drzezga, A.; Dietlein, M.; et al. Translational Development of a Zr-89-Labeled Inhibitor of Prostate-specific Membrane Antigen for PET Imaging in Prostate Cancer. Mol. Imaging Biol. 2021. [CrossRef] [PubMed]

250. Dietlein, F.; Kobe, C.; Munoz Vazquez, S.; Fischer, T.; Endepols, H.; Hohberg, M.; Reifegerst, M.; Neumaier, B.; Schomaecker, K.; Drzezga, A.E.; et al. An (89)Zr-labeled PSMA tracer for PET/CT imaging of prostate cancer patients. J. Nucl. Med. 2021. [CrossRef]

251. Noor, A.; Van Zuylekom, J.K.; Rudd, S.E.; Waldeck, K.; Roselt, P.D.; Haskali, M.B.; Wheatcroft, M.P.; Yan, E.; Hicks, R.J.; Cullinane, C.; et al. Bivalent Inhibitors of Prostate-Specific Membrane Antigen Conjugated to Desferrioxamine B Squaramide Labeled with Zirconium-89 or Gallium-68 for Diagnostic Imaging of Prostate Cancer. J. Med. Chem. 2020, 63, 9258-9270. [CrossRef]

252. Schafer, M.; Bauder-Wust, U.; Leotta, K.; Zoller, F.; Mier, W.; Haberkorn, U.; Eisenhut, M.; Eder, M. A dimerized urea-based inhibitor of the prostate-specific membrane antigen for 68Ga-PET imaging of prostate cancer. EJNMMI Res. 2012, 2, 23. [CrossRef] 